\title{
MICROCREDIT CONTRACTS, RISK DIVERSIFICATION AND LOAN TAKE-UP
}

\author{
Orazio Attanasio \\ Institute for Fiscal Studies
}

\author{
Britta Augsburg \\ University College London
}

\author{
Ralph De Haas \\ European Bank for Reconstruction and \\ Development and Tilburg University
}

\begin{abstract}
We study theoretically and empirically the demand for microcredit under different liability arrangements and risk environments. A theoretical model shows that the demand for joint-liability loans can exceed that for individual-liability loans when risk-averse borrowers value their long-term relationship with the lender. Joint liability then offers a way to diversify risk and reduce the chance of losing access to future loans. We also show that the demand for loans depends negatively on the riskiness of projects. Using data from a randomised controlled trial in Mongolia we find that these model predictions hold true empirically. In particular, we use innovative data on subjective risk perceptions to show that expected project risk negatively affects the demand for loans. In line with an insurance role of joint-liability contracts, this effect is muted in villages where joint-liability loans are available. (JEL: D14, D81, D86, G21, O16)
\end{abstract}

\section{Introduction}

The past few years have witnessed an intense debate on whether microcredit can lift people out of poverty. Advocates have long painted a picture in which many households escape poverty once they get access to small loans. However, more recently, doubts have emerged about whether microcredit systematically improves living standards. This scepticism has been fuelled by rigorous evidence from across seven countries which shows that when poor households get access to microloans this typically does not

The editor in charge of this paper was Dirk Krueger.

Acknowledgments: The authors thank Maitreesh Ghatak, Rachid Laajaj, Nathaniel Young and seminar participants at the Institute for Fiscal Studies (IFS), CERMi, Maastricht University, and LudwigMaximilians-Universität München for useful comments. We also thank the editor and three anonymous referees for useful feedback. Sam Crossman and Teodora Tsankova provided excellent research assistance. Any errors are the responsibility of the authors. The opinions expressed in this paper are those of the authors and do not necessarily represent the views of the EBRD. The related RCT is registered on www.socialscienceregistry.org under number AEARCTR-0000303.

E-mail: oraziopietro@gmail.com (Attanasio); britta_a@ifs.org.uk (Augsburg); dehaasr@ebrd.com (De Haas) 
lead to meaningful increases in either income or consumption (Banerjee et al. (2015) and Meager (2016b)).

One explanation for these insignificant average impacts is that relatively few people take up microcredit when it is offered to them. Low take-up rates may to some extent reflect a lack of creditworthy borrowers and profitable projects: lowquality potential borrowers may rationally self-select out of the credit market. Even among entrepreneurs that in principle could service debt there may be limited appetite to borrow (Johnston and Morduch (2008)). Low take-up may for instance reflect borrowers' dissatisfaction with the contractual structure of microcredit itself. That is, entrepreneurs that in principle would like to borrow may be dissuaded from doing so because of certain unattractive features of microcredit contracts and/or because of the riskiness of investment projects.

Moreover, recent advances in microcredit research suggest that even conditional on loan take-up, treatment effects may be small (see, for instance, the meta-analysis by Meager (2016a)) and concentrated among specific sub-populations (such as existing entrepreneurs, see Banerjee et al. (2017)). Developing a better understanding of how different types of microcredit contracts impact entrepreneurial decisions therefore remains of first-order importance. While theory has made substantial contributions to advance our understanding of this issue, empirical work has lagged behind. One contribution of this paper is to partially address this gap.

Microcredit contracts differ in many ways. An important question is therefore how microcredit can be turned into a more attractive and hence more effective tool to increase entrepreneurship and living standards. Recent evidence suggests that small design changes - such as introducing grace periods (Field et al. (2013)) or tailoring repayment schedules to the needs of individual borrowers (Beaman et al. (2015)) may affect how people use microcredit. This paper focuses on a quintessential feature of microcredit contracts: their liability structure.

In the early days of its existence, much attention was given to microcredit contracts in which borrowers form small groups and are jointly liable: they are responsible for the repayment of each other's loans. All group members are treated as being in default when at least one of them does not repay and all members are then denied subsequent loans. Such a feature, possibly exploiting informational advantages of clients relative to loan officers, was supposed to improve loan performance and raise repayment rates. The fact that joint-liability loans can also have a risk-sharing aspect received less attention in the literature. In this paper, we focus on this aspect, as it can possibly increase loan take-up in situations where projects are risky and where uncertainty is a salient component of the decision process.

The main idea, which we explore both theoretically and empirically, is that joint liability encourages risk sharing among group members and, therefore, reduces the risk involved in any given project. This may, in turn, lead to an increase in the proportion of borrowers that start a business (compared with individual-liability credit). To formalise this simple point, we develop a concise theoretical model where individuals choose whether to take up a loan for a risky project or to pursue a safe project. Risk-averse investors are less willing to take up a loan to finance a risky project the higher is the risk 
of such projects ${ }^{1}$ The model produces two main testable predictions. First, individuals are more likely to take up a loan when offered a joint-liability contract instead of an individual-liability one. Second, while in both contractual frameworks take-up rates go down with the risk of the project, this effect is muted for joint-liability contracts.

We provide empirical evidence on the relationship between risk and loan takeup that is consistent with these theoretical predictions. To do so, we exploit the data used in Attanasio et al. (2015), which contains detailed survey data from a randomised controlled trial (RCT) in Mongolia. As part of this RCT, individual-liability and jointliability credit was randomly introduced across villages (while no credit was introduced in a set of control villages). This unique set-up allows for a clean comparison of both types of liability structure while keeping other product features constant ${ }^{2}$

The analysis in Attanasio et al. (2015) focused on measuring the poverty impacts of both types of microcredit as well as comparing their repayment performance. We found a small positive impact of access to joint-liability loans (but not of individual-liability loans) on food and total consumption while there were no differences in repayment performance. An open question posed at the end of that paper is why joint-liability loans may have been more effective at raising consumption? This paper aims to at least partially answer this question by focusing on the differential loan take-up between both lending programs and by exploiting novel data on subjective returns expectations of investment projects in both treatment arms. In particular, we introduce the notion that perceived investment risk is an important determinant of loan take-up and, moreover, one that interacts strongly with the liability structure of the credit that is on offer.

To provide evidence for these hypotheses, we use as yet unexploited survey data on subjective returns expectations that were collected as part of the original RCT. The Mongolian survey data contain, for each respondent, crucial information about the subjective probability distribution of the returns on the investment project that could be financed by the newly available microcredit. Having elicited such subjective probability distributions through a number of questions we describe below, we can compute the riskiness of investment projects at the individual and (by averaging) at the village level. The use of subjective expectations and measures of riskiness derived from such expectations data is a novel feature of this paper. It allows us to relate differences in loan take-up between individual and joint-liability schemes to the (perceived) riskiness of the projects available to individuals across different villages. The two model predictions mentioned above can be used as a theoretical framework to interpret these results. Our results show that the subjective riskiness of projects negatively affects the demand for loans but that this effect is muted in villages where joint-liability loans are available. This result confirms the insurance role of jointliability contracts.

1. As is well known, the possibility of default introduces an important non-concavity in the objective function of borrowers which might induce them to prefer riskier projects. As this issue is not the focus of the paper, we assume that lenders impose a sufficiently large penalty upon default so as to avoid this issue.

2. Neither our theoretical model nor our empirical set-up allows borrowers to choose the liability structure of the microloans on offer. Instead, they are supplied with access to either joint or individual-liability credit. 
Our findings contribute to a rich literature on joint-liability lending that has emerged over the last two decades $\bigsqcup^{3}$ Theoretical work has explored how joint liability may reduce adverse selection (Ghatak (1999, 2000) and Gangopadhyay et al. (2005)); ex ante moral hazard by preventing excessively risky projects and shirking (Stiglitz (1990), Banerjee et al. (1994) and Laffont and Rey (2003)); and ex post moral hazard by preventing non-repayment in case of successful projects (Bohle and Ogden (2010)). While in models such as those developed by Ghatak and Guinnane (1999) joint liability fosters mutual insurance among group members, and consequently leads to better repayment performance, Besley and Coate (1995) and Allen (2016) show how (full) joint liability may also induce group borrowers to default strategically. More recently, De Quidt et al. (2016) compare joint-liability lending with two types of individualliability lending: with and without group meetings (which facilitate informal mutual insurance). They show that in a context of high social capital, individual-liability lending where borrowers are able to sustain informal mutual insurance (implicit joint liability) can improve upon explicit joint-liability lending in terms of borrower welfare and repayment.

On the empirical side, a small number of papers assess the impact of liability structure on repayment performance. Ahlin and Townsend (2007) test empirically the implications of different models with joint liability in the context of Thailand and find a negative relationship between the degree of joint liability, as proxied by the fraction of the group that is landless, and repayment. Giné and Karlan (2014) examine the impact of joint liability on repayment through two experiments in the Philippines. They find that removing joint liability, or introducing individual liability from scratch, did not affect repayment rates over the ensuing three years. In a related study, Carpena et al. (2013) exploit a quasi-experiment in which an Indian lender switched from individual to joint liability, the reverse of the switch in Giné and Karlan (2014). They find that joint liability significantly improved repayment rates. Mahmud (2015) explores the shift by a Pakistani microfinance institution from individual-liability lending (guaranteed by a non-borrower) to joint-liability lending (without mandatory group meetings) and documents a significant improvement in repayment behaviour (among those that decide to take up a loan under the new joint-liability regime).

Unlike this earlier theoretical and empirical work, our main focus is not so much on repayments but on the take-up of productive investments. Whilst we do not discuss the specific credit-market frictions, such as moral hazard and adverse selection, that prevent the financing of these projects in the absence of a micro-lender, we consider the impact of joint liability relative to individual liability on risk taking and investment behaviour. This issue has been explored to a lesser extent in the literature and remains ambiguous ${ }^{4}$ On the one hand, joint liability may encourage risk taking if clients expect to be bailed out by co-borrowers as part of the mutual insurance mechanism inherent

3. See Ghatak and Guinnane (1999) for a comprehensive early summary.

4. Early seminal contributions on informal insurance arrangements are Coate and Ravallion (1993) and Ligon et al. (2002). In these models, risk-averse individuals agree on an informal risk-sharing arrangement that, while legally not enforceable, is credible due to expected future reciprocity. 
to joint-liability contracts. On the other hand, joint liability may reduce moral hazard if borrowers monitor each other and if there is a credible threat of punishment, for instance through social sanctions, in case a co-borrower defaults. Giné et al. (2010) find, based on laboratory-style experiments in a Peruvian market, that contrary to much of the theoretical literature, joint liability stimulates risk taking - at least when borrowers know the investment strategies of co-borrowers. When borrowers could selfselect into groups there was a strong negative effect on risk-taking due to assortative matching. Fischer (2013) undertakes similar laboratory-style experiments and also finds that under limited information, joint liability stimulates risk taking as borrowers free-ride on the insurance provided by co-borrowers ${ }^{5}$ When co-borrowers have to give upfront approval for each others' projects, ex ante moral hazard is mitigated ${ }^{6}$

The results of our theoretical model are consistent with those of Fischer (2013) and Giné et al. (2010). Our contribution is to focus on the interaction between the liability structure of microcredit and borrowers' own perceptions of the local risk environment. In particular, we show that joint liability can substantially reduce, or even fully offset, the negative effect of expected project risk on loan take-up.

The remainder of this paper is structured as follows. We start by presenting our theoretical model (Section 2) and then describe the data we use to check whether our model predictions hold true in the given context (Section 3 ). Section 4 presents our findings and a number of robustness tests, after which we conclude in Section 5

\section{Risk Sharing in a Model of Microcredit with Different Liability Contracts}

Unlike earlier papers in the microcredit literature, our emphasis is not on repayments but on the take-up of productive investments. The main idea that we want to outline is that joint liability might encourage (or provide an institutional setting that allows) risk-sharing among group members as, de facto, it reduces the amount of risk involved in a given project. Joint liability may therefore lead to an increase in the proportion of borrowers that start a business. We use the predictions of our model to provide an interpretation of the results we obtain using data collected as part of a randomised controlled trial.

\subsection{General Set-Up}

We consider individuals who can either invest in a productive but risky project or in a safe project. Each individual is endowed with a quantity $D$. If invested in the

5. Wydick (1999) provides empirical evidence from Guatemala on intra-group insurance against idiosyncratic risks.

6. A related empirical literature investigates the introduction of formal insurance products on risk-taking in settings where (imperfect) informal insurance is available. Mobarak and Rosenzweig (2013) find that the introduction of formal (rainfall) insurance, which complemented informal insurance networks among households, increased risk-taking among Indian farmers by incentivising them to switch to higher-risk, higher yield crop varieties. 
safe project, $D$ provides a certain return of $D R^{s}$. We can think of this as financing consumption or some very simple activity that is not particularly risky or productive.

All individuals also have access to a risky project. This risky project requires an investment of $D+B$, with $B$ considerably larger than $D$. We assume that investing in the risky project yields a return of $R^{L}$, which is a random variable with probability density function $f\left(R^{L}\right)$ and support $\left[0, \bar{R}^{L}\right]$. There is a lender that supplies loans of size $B$ to finance the project at a rate $R^{B}$. In order for an individual to afford the repayment of the loan, the realised return on the risky investment must satisfy the condition $R^{L}(D+B) \geq R^{B} B$. We define $A=\left(R^{B} B\right) /(D+B)$ as the minimal realisation of $R^{L}$ that allows the individual to repay an individual-liability loan. We assume that when the realised return on the risky investment is less than $A$ the borrower will default and repay nothing. As discussed below, default has a cost. We further assume that $E\left[R^{L}\right]>A>R^{B}>R^{s}$; that the outcome of the project is perfectly verifiable by the lender; and that repayments (assuming that $R^{L}(D+B) \geq R^{B} B$ ) are enforceable.

Although the model is static (we consider only one period), we assume that the relationship with the lender is valued by the borrower and default upon a loan involves a loss. The relationship between the borrower and the lender may be of a long-term nature: default may jeopardise this long-term relationship and thus will involve a cost. We therefore assume that the maintenance of this relationship is valued at some exogenous amount $K$ (which we define in terms of "utils") 7

At the end of the period, individuals enjoy utility that depends on whether they chose the safe or risky project and, in the latter case, on the realisation of the random variable $R^{L}$, the return on the risky investment. If they do not default on the loan (either because they invested in the safe asset or because they invested in the risky asset and repaid on time) they also obtain the aforementioned $K$ utils. $K$ represents the reputation with the lender and the associated availability of future loans (which may moreover come at a lower interest rate if the lender rewards repeat borrowing). If default is publicly observable in the local community, $K$ may also include the preservation of social collateral.

The individuals in our model economy are heterogeneous in $R^{S}$, that is, there are differences in the returns to the safe project, such as home production. We need this heterogeneity to allow some individuals to borrow while others do not. All individuals share the same utility function, which is increasing and concave, as well as the utils that they derive from the long-term relationship with the lender. Finally, all individuals consume an amount $y$ which is exogenous and cannot be recovered by the lender.

We now consider two types of contract: individual liability and joint liability. For simplicity, we assume that joint liability groups include only two individuals and that

7. Allen (2016) presents a model in which the value of future borrowing determines the optimal level of joint liability. If liability is lower or higher than the value of a continued lending relationship then withingroup risk sharing is reduced or strategic default among borrowers is induced, respectively. 
individuals form groups with other individuals with a similar $R^{s}$ to themselves ${ }^{8}$ Note that both in the model and in our empirical set-up individuals do not choose the contract type that is on offer to them.

2.1.1. The Individual-Liability Contract. When an individual does not take up a loan, she retains the long-term relationship with the lender. When an individual liability loan is taken and the project is successful (that is, if $R^{L}>A$ ), the borrower repays $R^{B} B$ and preserves her long-term relationship with the lender. If the project is unsuccessful, the borrower retains her realised return $\left(R^{L}(D+B)\right)$ but loses her relationship with the lender and the associated utils $(K)$. In either scenario the individual also consumes the exogenous amount $y$. We therefore assume that under individual liability, an individual who does not take up a loan achieves utility $u\left(y+R^{s} D\right)+K$, where $u$ is a concave utility function. An individual who takes up a loan achieves utility $u\left(y+R^{L}(D+B)-R^{B} B\right)+K$ if she can repay the loan, that is if $R^{L}>A$ and utility $u\left(y+R^{L}(D+B)\right)$ if $R^{L}<A$. This last assumption is in line with anecdotal evidence from the field. Notice that $R^{L}$ is a random variable and that we assume that no repayment is made when $R^{L}<A$. Expected utility, in this case, when an individual takes up a loan, is given by

$$
\begin{aligned}
E\left[u^{\text {indiv. }}\right]= & \int_{0}^{A} u\left(y+R^{L}(D+B)\right) f\left(R^{L}\right) d R^{L} \\
& +\int_{A}^{\overline{R^{L}}}\left[u\left(y+R^{L}(D+B)-R^{B} B\right)+K\right] f\left(R^{L}\right) d R^{L}
\end{aligned}
$$

2.1.2. The Joint-Liability Contract. In the case of joint liability, we assume that the two borrowers are identical in the product $D R^{S}$. That is, individuals are matched in groups with similar individuals in the one dimension of heterogeneity that we are considering. We also assume that the returns to the risky projects that the two individuals are considering are drawn from the same distribution $f\left(R^{L}\right)$. This symmetry assumption simplifies the analysis and is not crucial for the point we want to make. However, in Appendix A we report evidence supporting this assumption. For simplicity, we also assume that the outcomes of the two projects are not only identically distributed but also independent.

The two individuals in a group are jointly liable for their loans. As they are identical, they make the same choices. If they choose the safe project and do not take up a loan, they both receive $D R^{s}$ and preserve the long-term relationship with the lender. If they take up a loan, even from the point of view of a single individual we need to

8. When we consider different degrees of risk aversion we obtain very similar results. Note that in our experiment matching was endogenous and take-up was high, suggesting that assortative matching took place. Appendix A provides evidence that individuals within a group are indeed characterised by similar risk attitudes. See Ahlin (2009) for related evidence from Thailand. 
consider what happens to her partner. Therefore, instead of the two cases considered in the individual-liability case, we need to consider six different possibilities. Denoting with $R^{L}$ the rate of return for the investment of individual 1 , and with $\tilde{R}^{L}$ the return for individual 2, these six cases are:

$$
\begin{aligned}
& \text { Case } 1: R^{L} \geq A, \tilde{R^{L}} \geq A \\
& \text { Case } 2: R^{L} \geq 2 A-\tilde{R^{L}}, \tilde{R^{L}}<A \\
& \text { Case } 3: R^{L}<A, \tilde{R^{L}} \geq 2 A-R^{L} \\
& \text { Case } 4: R^{L} \geq A, R^{L} \leq 2 A-\tilde{R^{L}}, \tilde{R^{L}}<A \\
& \text { Case } 5: R^{L}<A, \tilde{R^{L}} \leq 2 A-R^{L}, \tilde{R^{L}} \geq A \\
& \text { Case } 6: R^{L}<A, \tilde{R^{L}}<A
\end{aligned}
$$

The six cases are easily understood on the basis of Figure 1, which depicts them in the $\left(R^{L}, \tilde{R^{L}}\right)$ space. In case 1 , both individuals' projects are successful and they both repay their loan and interest and hence preserve the long-term relationship with the lender. In case 2 (3), individual 2 (1) is unsuccessful but individual 1 (2) realises a large enough return on their own investment that they can "bail-out" the other individual by making up the difference between $R^{B} B$ and their borrowing partner's realised return. Due to the bail out, both individuals maintain the long-term relationship with the lender. In cases 4, 5 and 6, at least one of the individuals is unsuccessful, and the other's return is such that they are together unable to meet their joint repayment requirement. Consequently both lose their relationship with the lender (but keep their own realised returns). In all cases, both individuals consume the exogenous amount $y$.

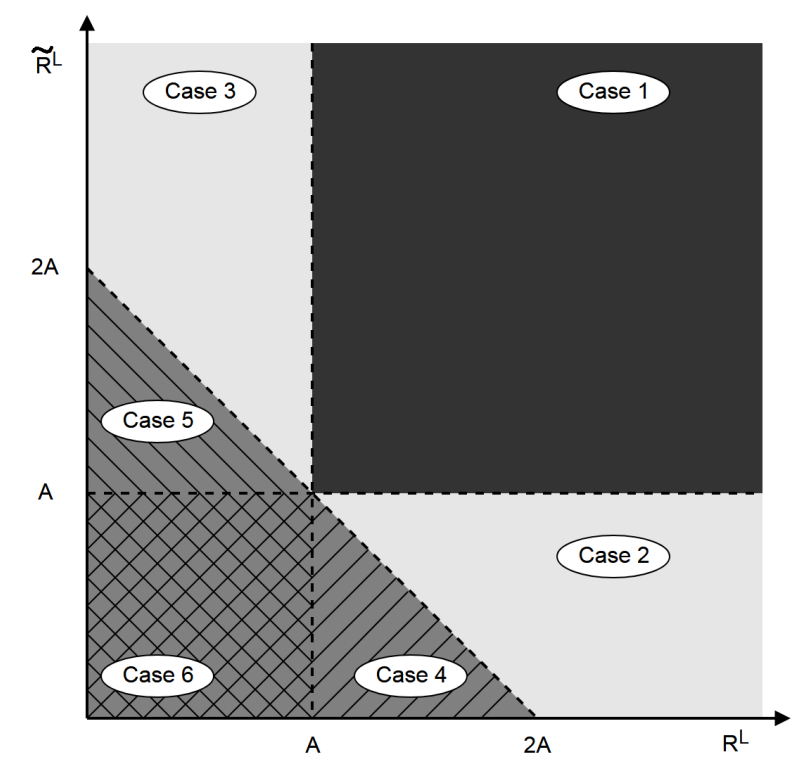

FIGURE 1. Outcome possibilities in a joint-liability group consisting of two members. 


\subsection{Theoretical Results}

We now present four propositions. The first provides a way to characterise the proportion of loan takers in terms of the variable $R^{s *}$, which describes individual heterogeneity. The second provides a relation between the variance of the risky investment projects and the proportion of loan takers. These two propositions are standard and set the base for the following two that characterise differences between individual and joint-liability contracts. The last two are useful to provide a framework to interpret our empirical results.

Proposition 1. Under individual liability, there exists a level of returns to the safe project $R^{s}, R^{s *}$, such that individuals with $R^{s}>R^{s *}$ invest in the safe projects and individuals with $R^{s} \leq R^{s *}$ apply for a loan from the lender. Analogously, under joint liability, there is a level of returns to the safe project $R^{s}, R^{s * *}$, such that individuals with $R^{s}>R^{s * *}$ offered a joint-liability loan invest in the safe projects and individuals with $R^{s} \leq R^{s * *}$ offered a joint-liability loan take it up to finance the risky project.

Proof. The proof of this proposition follows from the consideration of the expected utility under the two alternatives and from the fact that the excess return on the risky project is monotonic and decreasing in $R^{s}$.

This proposition is very intuitive and does not merit special discussion. It simply characterises how this model works and is used to understand the propositions that follow. In this model, we perform comparative statics exercises by studying the effects of changes in fundamentals on $R^{s *}$ and $R^{s * *}$.

Proposition 2. Consider a distribution of $R^{L}, g\left(R^{L}\right)$ (with $c d f G\left(R^{L}\right)$ ) which is a mean-preserving spread of $f\left(R^{L}\right)$. If $K$ is sufficiently large, both under individual liability and joint liability, the fraction of individuals that take up a loan is smaller under $g\left(R^{L}\right)$ than under $f\left(R^{L}\right)$ in the sense that both $R^{s *}$ and $R^{s * *}$ are lower under $g\left(R^{L}\right)$ than under $f\left(R^{L}\right)$.

\section{Proof. See Appendix B.}

This proposition indicates that an increase in the riskiness of the investment project decreases the proportion of individuals that take up the loan, both under individual and joint liability. As mentioned above, the presence of the possibility of default for low values of the return makes the utility function non-concave over a region of the domain of $R^{L}$, so that to obtain the result we need a sufficiently large $K$.

It should be said that the size of $K$ required for Proposition 2 to hold, is different in the individual- and joint-liability cases, as shown in Appendix B. It turns out that an assumption on the size of $K$ is also necessary to obtain a proposition that compares joint- and individual-liability contracts. 
Assumption 1. Suppose that $\mathrm{K}$ is such that

$$
K>\frac{E\left[u^{\text {indiv.* }}\right]-E\left[u^{\text {joint* }}\right]}{\left(F(A)-\int_{0}^{\overline{R^{L}}} \int_{0}^{2 A-R^{L}} f\left(\tilde{R^{L}}\right) d \tilde{R^{L}} f\left(R^{L}\right) d R^{L}\right)}
$$

where

$$
\begin{aligned}
E\left[u^{\text {indiv.* }}\right]= & \int_{0}^{A} u\left(y+R^{L}(D+B)\right) f\left(R^{L}\right) d R^{L} \\
& +\int_{A}^{\overline{R^{L}}} u\left(y+R^{L}(D+B)-R^{B} B\right) f\left(R^{L}\right) d R^{L}
\end{aligned}
$$

is the expected utility from investing in the risky asset under the individual-liability contract - ignoring any potential utility from retaining relations with the lender $(\mathrm{K})$ and

$$
\begin{aligned}
E\left[u^{\text {joint* }}\right]= & \int_{0}^{2 A} \int_{0}^{2 A-R^{L}} u\left(y+R^{L}(D+B)\right) f\left(\tilde{R^{L}}\right) d \tilde{R^{L}} f\left(R^{L}\right) d R^{L} \\
& +\int_{0}^{A} \int_{2 A-R^{L}}^{\overline{R^{L}}} u(y) f\left(\tilde{R^{L}}\right) d \tilde{R^{L}} f\left(R^{L}\right) d R^{L} \\
& +\int_{A}^{\overline{R^{L}}} \int_{2 A-R^{L}}^{A} u\left(y+\left(R^{L}+\tilde{R^{L}}\right)(D+B)-2 R^{B} B\right) f\left(\tilde{R^{L}}\right) d \tilde{R}^{L} f\left(R^{L}\right) d R^{L} \\
& +\int_{A} \int_{A}^{R^{L}} \frac{R^{L}}{R^{L}} u\left(y+R^{L}(D+B)-R^{B} B\right) f\left(\tilde{R^{L}}\right) d \tilde{R}^{L} f\left(R^{L}\right) d R^{L}
\end{aligned}
$$

is the expected utility from investing in the risky asset under the joint-liability contract, again ignoring potential utility gains from a retained relationship with the lender.

This assumption easily delivers the following proposition.

Proposition 3. If Assumption 1 holds, the fraction of individuals that apply for the loan under joint liability is higher than the one under individual liability.

Proof. See Appendix B.

The intuition behind this proposition is quite simple and becomes clear by rearranging Assumption 1: 


$$
K\left\{\left(1-\int_{0}^{\overline{R^{L}}} \int_{0}^{2 A-R^{L}} f\left(\tilde{R^{L}}\right) d \tilde{R^{L}} f\left(R^{L}\right) d R^{L}\right)-(1-F(A))\right\} \geq E\left[u^{\text {indiv.* }}\right]-E\left[u^{\text {joint* }}\right]
$$

The expression in braces on the left-hand side is the expected probability of successfully repaying the loan under the joint-liability contract, minus the probability of repaying under the individual-liability contract. Hence the entire expression on the left-hand side is the expected increase in utils that comes from the insurance effect of entering a joint-liability contract rather than an individual one. Under joint liability, an individual is more likely to maintain a relationship with the lender, and enjoy the benefits that accrue from this, because even in cases when they do not meet their own repayment requirement $(A)$, they may still be bailed out if their partner's realisation of $\tilde{R^{L}}$ is sufficiently large (specifically, if $\tilde{R^{L}} \geq 2 A-R^{L}$ ).

The expression on the right-hand side is the change in expected utility that arises from the different mean returns under the two different contracts. Under joint liability the mean return from the investment is lower because there are now additional states of the world where the individual must bail out their partner (and thus give up $R^{B} B-\tilde{R^{L}}(D+B)$ of their own return) or be bailed out (and thus give up their realisation of $R^{L}(D+B)$ to their partner as a partial payment of their debt). Thus Assumption 1 states that when the insurance effect dominates this mean return effect, the joint-liability contract induces a greater fraction of individuals to apply for credit.

We now consider again the mean-preserving spread used in Proposition 2 to characterise how the increase in risk affects loan take-up differentially across different types of contracts. We need, however, to specify an additional assumption on the magnitude of the exogenous utility gain from succeeding in repaying the lender.

Assumption 2. Suppose that $\mathrm{K}$ is such that

$$
K \geq u\left(y+R^{B} B\right)-u(y)
$$

This ensures that the exogenous number of utils that individuals receive upon repayment of their loan is sufficiently large to make repayment desirable at the margin (at $R^{L}=A$ ). This in turn delivers Proposition 4:

Proposition 4. Suppose Assumptions 1 and 2 hold. Then the negative effect of the variance of the project on loan take up is larger under individual liability than under joint liability. That is

$$
E_{G}\left[u\left(y+R^{s *} D\right)\right]-E_{F}\left[u\left(y+R^{s *} D\right)\right]<E_{G}\left[u\left(y+R^{s * *} D\right)\right]-E_{F}\left[u\left(y+R^{s * *} D\right)\right]
$$

or equivalently

$$
R^{s G *}-R^{s F *}<R^{s G * *}-R^{s F * *}
$$

where $R^{s G *}, R^{s F *}, R^{s G * *}$, and $R^{s F * *}$ are the cut-off safe interest rates under individual and joint liability contracts under the $F$ and $G \mathrm{cdfs}$. 


\section{Proof. See Appendix B.}

This final proposition, expressed both in terms of utility and cutoff interest rates that in our model determine the proportion of loan takers, establishes that the negative effect of an increase in risk on loan take-up is smaller under joint liability. We bring this proposition to the data and use it to interpret our results in what follows 9

\section{Data}

In this section, we describe the experimental data we use to study the impact that the offer of different liability structures has on the take-up of loans and interpret the results in the light of our model's structure.

\subsection{The Experiment}

To assess the impact that risk perceptions and different types of contracts have on loan take-up, we need a setting that provides substantial cross-sectional heterogeneity in investment risk, empirical measures to gauge potential borrowers' own perceptions of this risk, and exogenous variation in the liability structure of the microcredit contracts on offer. We use data collected as part of the impact evaluation of a microfinance initiative that satisfy these three requirements. The evaluation implemented a randomised field experiment among 1,148 relatively poor women in 40 villages across five rural provinces in Mongolia. The aim of the experiment was to measure and compare the impact of individual-liability contracts with the impact of jointliability microcredit contracts on various poverty outcomes. The measurements of a variety of outcomes were complemented by the elicitation of subjective perceptions of investment risk and returns. The findings about the impact of the availability of microfinance on several outcomes are discussed in Attanasio et al. (2015), who also

9. The model assumes that, due to randomisation, the distributions of project returns do not differ systematically between the joint-liability and individual-liability villages. While it is difficult to provide conclusive evidence for this assumption, we do have access to respondents' subjective assessment of the revenues of their project in the worst-case and best-case scenarios (cf. Section 3.3). When we take the best-case expectations as a proxy for the upper bound of the revenue distribution, we cannot reject the hypothesis that the initial mean is similar in both village types ( $\mathrm{p}$-value $=0.22$ ). If liability structure would impact investment decisions (and therefore the returns distribution), this could materialise in our setting if respondents, once they receive access to a certain type of microcredit, abandon their investment plans. To check whether systematic selection effects occurred, we average maximum revenue expectations across all borrowers in the individual-liability villages and then do the same for the joint-liability villages. Under the assumption that conditional on investing, people indeed invested in the same projects that they mentioned before they knew the randomisation outcome, we expect that the average best-case return of projects is the same in both village types if - as per our model - this return is not affected by the liability structure. In contrast, if the liability structure on offer systematically dissuaded borrowers from carrying out certain types of projects, then the average best-case return of projects by respondents that did take up a loan may start to differ between both types of villages. We find that the average best-case returns for those that took up loans do not differ significantly between both village types ( $p$-value $=0.16$ ). 
provide a detailed description of the experimental set-up and data collection. We provide a brief summary here.

The 40 villages were randomised into three groups: 10 villages did not receive loans from the implementing partner; in 15 villages individual-liability loans were offered; and in a further 15 villages joint-liability loans were offered. Before randomisation, extensive baseline data were collected from women who were interested in taking up a microloan. These women were identified during information sessions that were held in February 2008. The data used in this paper therefore refer to respondents who had expressed an interest in borrowing before they knew whether they would be offered a loan as part of the experiment and, if so, whether this would be an individual- or a joint-liability loan.

TABLe 1. Descriptive statistics and treatment-control balance.

\begin{tabular}{|c|c|c|c|c|c|c|c|c|}
\hline & \multirow[b]{2}{*}{ Obs } & \multicolumn{3}{|c|}{ Control Group } & \multicolumn{2}{|c|}{ Indiv - Control } & \multicolumn{2}{|c|}{ Group - Control } \\
\hline & & Obs & Mean & St. Dev. & Coeff. & p-value & Coeff. & $p$-value \\
\hline Respondent age & 961 & 260 & 40.881 & 9.360 & -1.521 & 0.179 & -0.506 & 0.337 \\
\hline Respondent education $(<=$ VII $)$ & 961 & 260 & 0.150 & 0.358 & -0.013 & 0.754 & -0.021 & 0.289 \\
\hline Respondent religion( $1=$ Buddhist $)$ & 961 & 260 & 0.758 & 0.429 & -0.058 & 0.375 & 0.000 & 0.998 \\
\hline \multicolumn{9}{|l|}{ Household composition } \\
\hline \# members & 961 & 260 & 4.888 & 1.828 & -0.048 & 0.851 & 0.047 & 0.712 \\
\hline$\#$ adults ( $>=16$ years old) & 961 & 260 & 1.754 & 1.255 & 0.009 & 0.958 & 0.005 & 0.950 \\
\hline \# children $(<16$ years old $)$ & 961 & 260 & 3.158 & 1.530 & -0.069 & 0.720 & 0.032 & 0.746 \\
\hline \multicolumn{9}{|l|}{ Self-employment activities } \\
\hline Any type of enterprise & 961 & 260 & 0.60 & 0.490 & -0.012 & 0.849 & 0.000 & 0.998 \\
\hline $\begin{array}{l}\text { Respondent has own enterprise } \\
\text { Other employment activities }\end{array}$ & 961 & 260 & 0.396 & 0.490 & -0.005 & 0.937 & -0.016 & 0.566 \\
\hline$\#$ of non self-empl. income sources & 961 & 260 & 0.546 & 0.742 & 0.042 & 0.646 & 0.062 & 0.227 \\
\hline Wages from agricultural work & 961 & 260 & 0.088 & 0.285 & 0.037 & 0.361 & 0.021 & 0.227 \\
\hline Wages from private business & 961 & 260 & 0.119 & 0.325 & 0.006 & 0.834 & 0.023 & 0.175 \\
\hline Wages from mining & 961 & 260 & 0.023 & 0.150 & -0.012 & 0.517 & 0.011 & 0.332 \\
\hline Wages from teaching & 961 & 260 & 0.112 & 0.315 & -0.009 & 0.786 & -0.014 & 0.369 \\
\hline Wages from government & 961 & 260 & 0.100 & 0.301 & 0.014 & 0.737 & 0.003 & 0.882 \\
\hline Income from benefits & 961 & 260 & 0.850 & 0.358 & -0.027 & 0.457 & 0.000 & 0.976 \\
\hline Any other income & 961 & 260 & 0.073 & 0.261 & 0.030 & 0.412 & 0.010 & 0.517 \\
\hline Household asset index & 961 & 260 & 0.06 & 0.95 & -0.115 & 0.414 & 0.00 & 0.973 \\
\hline \multicolumn{9}{|l|}{ Risk measures } \\
\hline Individual-level risk & 952 & 257 & 0.204 & 0.035 & 0.010 & 0.393 & -0.001 & 0.887 \\
\hline Village-level risk & 961 & 260 & 0.152 & 0.032 & 0.016 & 0.240 & 0.006 & 0.356 \\
\hline
\end{tabular}

Notes: Household (business) asset index: Calculated for a list of home electrical appliances (business assets). Each asset is given a weight using the coefficients of the first factor of a principal-component analysis. Each index, for a household $\mathrm{i}$, is calculated as the weighted sum of standardised dummies equal to 1 if the household owns the durable good. The individual and village-level risk measures are coefficients of variation. Source: Baseline household survey and author calculations. Sample: All respondents that were interviewed at both baseline and endline.

Table 1 provides a brief overview of all respondents in the sample that were interviewed at both baseline and endline. On average, the women were 41 years of age and $85 \%$ of them had received formal schooling for more than seven years. The respondents lived in households of on average five members, three of which were children below the age of $16.60 \%$ of the women interested in a loan lived in a household that had a business and in $40 \%$ of cases the women owned a business themselves. The business was typically the only source of income. As mentioned above, the lender explicitly focused on relatively poor women. This is reflected in the 
fact that the average household in our sample earned MNT 1,100,000 (\$955) per year 10 which compares to an average rural household income of MNT 3,005,000 $(\$ 2,610)$ in 2007 (Mongolian statistical office). The last four columns of Table 1 also show that randomisation was successful. None of the presented variables shows any imbalances between the intervention arms 11

After the baseline survey, villages were randomised into the intervention arms and lending groups were formed in the villages that were allocated to the joint-liability treatment. The treatment period during which the lender provided loans in both types of villages lasted 1.5 years: from March 2008 to September 2009. During this period, participating women in treatment villages could apply for (repeat) loan 12 , while the lender refrained from lending in the control villages. At the end of the period a detailed follow-up survey was conducted among the respondents in all 40 villages.

The sample we use in this paper differs from the full experimental sample for two reasons. First, we exclude control households as we are interested in a comparison between households that receive access to individual-liability versus joint-liability microcredit. Second, our main outcome variable-whether a respondent applied for credit or not-is constructed by linking the survey data to administrative data from our implementing partner. During this data merge we lose 13 observations.

\subsection{The Loan Products}

As in the model, which assumes that loans are taken up to invest in a productive project, the purpose of both the individual and the joint-liability loans was to finance small-scale entrepreneurial activities ${ }^{13}$ Table 2 provides an overview of the main loan features.

Given the focus on business creation and expansion, loans had a grace period of either two months (loans exceeding six months) or one month (shorter loans). The average maturity and loan size differed by liability structure. Most joint-liability loans were composed of individually approved sub-loans with a maturity of between 3 and 12 months depending on the loan cycle (within a group all sub-loans had the same maturity). The maturity of individual-liability loans was slightly longer. The average size of the first joint-liability loan was USD 279 as compared with USD 411 for individual loans (see also Section 4.3).

The interest rate of both types of loans varied between $1.5 \%$ and $2 \%$ per month and was reduced by $0.1 \%$ after each successful loan cycle. Other dynamic incentives included the possibility to increase the loan amount and/or maturity after each repaid

10. We define earnings as entrepreneurial profits plus wages from formal employment by all household members. Social benefits are excluded.

11. Attanasio et al. (2015) provide a more detailed discussion of the treatment-control balance at baseline.

12. Of all borrowers $47 \%$ received at least one repeat loan during the experiment.

13. Besides agriculture - both animal husbandry and crop growing - the main village industries are baking, wood-processing, retail activities and felt making. 
TABLE 2. The loan products.

\begin{tabular}{|c|c|c|}
\hline Monthly interest rate & \multicolumn{2}{|l|}{1.5 to $2 \%$} \\
\hline Grace period & \multicolumn{2}{|c|}{ One or two months depending on loan maturity } \\
\hline Repayment frequency & \multicolumn{2}{|c|}{$\begin{array}{l}\text { Monthly, no public repayment meetings. In case of joint-liability loans, the group leader collects } \\
\text { and hands over repayments to the loan officer }\end{array}$} \\
\hline Progressive traits & \multicolumn{2}{|c|}{ Larger loans, lower interest rate and longer maturity after each repaid loan } \\
\hline \multirow[t]{2}{*}{ In case of default } & \multicolumn{2}{|c|}{ Loss of access to future loans (for the whole group in case of joint-liability loans) } \\
\hline & Individual-liability loans & Joint-liability loans \\
\hline Liability structure & Individual & Joint \\
\hline Average maturity $1^{\text {st }}$ loan & 224 days & 199 days \\
\hline Average maturity $2^{\text {nd }}$ loan & 234 days & 243 days \\
\hline Average size $1^{\text {st }}$ loan & USD 411 & USD 279 \\
\hline Average size $2^{\text {nd }}$ loan & USD 472 & USD 386 \\
\hline Collateral & Flexible approach & $\begin{array}{l}\text { Joint savings ( } 20 \% \text { of loan) sometimes supple- } \\
\text { mented by assets }\end{array}$ \\
\hline
\end{tabular}

Notes: This table describes the main characteristics of the individual and joint-liability loans. Average loan size is conditional on having a loan. Average loan size of joint-liability loans refers to loans per borrower not per group. Loans were disbursed in tögrög not USD.

loan. In our model these dynamic incentives are reflected in $K$, the amount at which borrowers value the relationship with the lender.

Group members had to agree among themselves who would apply for a loan and for what purpose. The lender then screened each application and if a project was deemed too risky, the lender would exclude that applicant while the other members could still get a loan. Group leaders were responsible for monitoring and collecting monthly repayments and handing them over to the loan officer. In line with our model, borrowers would lose access to future loans from the institution in case of default. Joint-liability contracts stated explicitly that the lender would terminate lending to the whole group if a group member did not fully repay a loan.

There were no public repayment meetings ${ }^{14}$ Groups decided themselves on the modalities of their cooperation, including whether to meet regularly or not, and if so, how frequently (typically once per month). The joint-liability loan was therefore more flexible than "traditional" group lending, which borrowers often consider burdensome due to the frequent and lengthy repayment meetings (Wydick $(1999)){ }^{15}$

The lender took a flexible approach towards collateral in which loan officers decided whether collateral was requested or not. In the case of joint-liability loans, some groups needed to save an amount equivalent to $20 \%$ of the loan size before the loan would be disbursed (the joint savings were then used as collateral). Our data show that on average $66 \%$ (91\%) of all first-time joint-liability (individual liability) loans were (partially) collateralised. The lower prevalence of collateral in joint-liability

14. Field and Pande (2008) randomly assign weekly or monthly repayment meetings (for individualliability loans) and find that a lower-frequency schedule can significantly reduce transaction costs without increasing defaults. However, building on the same experiment, Feigenberg et al. (2013) show that more frequent meetings have a positive impact on borrowers' social capital and pro-social behaviour. In the longer term this resulted in lower default rates on borrowers' second loans (even though all borrowers had by that time reverted to the same repayment frequency).

15. In Giné and Karlan (2014) weekly meetings were held in both individual and joint-liability villages. 
villages is to be expected as the joint-liability structure (and the associated reliance on social capital) de facto acts as a partial substitute for traditional collateral. This lower prevalence may partially explain the higher take-up of joint-liability loans that we document (at least in the presence of higher investment risk).

\subsection{Measuring Investment Risk}

3.3.1. Eliciting Subjective Expectations About Entrepreneurial Returns. To test our model predictions we need information on the investment risks as perceived by potential borrowers themselves. Our baseline survey data contain unique primary information on the subjective probability distribution of the returns on the investment projects that could be financed by the newly available microcredit. The survey asked all participants that intended to use the loan for a business investment (83\% of all participants) ${ }^{16}$ about the expected maximum and minimum values that future returns could take. The specific wording of the questions was: "If the enterprise were to be extremely successful, how much total gross revenue/total sales would you expect to make over the next 12 months (in togrog)?" and "If the enterprise turned out to be extremely unsuccessful, how much total gross revenue/total sales would you expect to make over the next 12 months (in togrog)?". We note that, rather than asking a question about profits, respondents were asked a question about revenues. While this is unfortunate, the correlation between profits and revenue at baseline is above 0.55 . Moreover, the relation between costs and revenues does not differ systematically between loan applicants in individual-liability villages versus joint-liability villages.

After getting an answer, the interval defined by the minimum and maximum was partitioned into two equal intervals and respondents were asked to assess the probability that future revenue would be below and above the average value. The specific wording of the questions was: "How likely do you think it is that in the next 12 months, this enterprise's total gross revenue/total sales will be above the average revenue amount [xxx]?" and "How likely do you think it is that in the next 12 months, this enterprise's total gross revenue/total sales will be below the average revenue amount $[x x x]$ ?" In other words, we elicited information about the cumulative distribution function (CDF) of future returns. By making assumptions about the functional form of the distribution, this data can then be used to construct moments of the expected return distribution, including means and standard deviations 17

16. We asked respondents "If you were to receive a loan from XacBank, what would you mainly use it for?" and only if the answer was "set-up an enterprise"; "fund existing enterprise"; "set-up/contribute to joint enterprise"; or "set-up/contribute to partner's enterprise" did we ask the expectation questions.

17. As an alternative to making distributional assumptions, one can simply use the average of the minimum and maximum as a measure of location and their difference as a measure of uncertainty. Our results hold independently of whether we use the coefficient of variation to measure investment risk (which requires functional form assumptions) or the range of expected returns (calculated without any such assumptions). We present results based on the coefficient of variation and provide robustness tests using the simpler measure in Table 8 . The fact that results are very comparable is in line with findings by Attanasio et al. (2005); Attanasio and di Mario (2008); and Delavande et al. (2011b). 
Whilst the questions on the minimum and maximum were relatively easy to ask, the questions involving a probability statement were somewhat more challenging ${ }^{18}$ In a developing country context, the majority of respondents typically have little schooling and may not be familiar with the concept of probabilities and probability laws. We therefore took the time to carefully explain, with the help of visual aids, these concepts to the respondent and conducted a practise round. We elicited the probabilities with the help of a ruler that had numbers from 0-100. During the practice round, we asked respondents about the likelihood that it would snow tomorrow. The respondent was asked to point to 0 if she was absolutely sure that it would not snow the next day, and to 100 if she was sure it would snow, and a number closer to 100 than to 0 if she was not absolutely sure but perceived it more likely to snow than not.

There are two restrictions we could have imposed during the survey to ensure that responses adhere to theory. The first concerns the expected minimum and maximum returns. There is a discussion in the literature as to whether the reported values truly reflect the maximum (minimum) or some very high (low) quantile (see, for example, McKenzie et al.(2013)) and hence whether reported probabilities of zero or one should be imposed. We decided to impose this restriction neither during the elicitation process nor in our analysis. This is in line with Delavande et al. (2011a) who show that, at least in the specific context they analyse, respondents seem to associate some high percentile with "the maximum". Also some of our respondents appear not to report the true minimum or maximum and we discuss this in more detail in Appendix F.

Second, the two reported probabilities should in theory add up to one. We could have imposed this condition during data elicitation, or alternatively, we could have only asked one of the probabilities and calculate the second, assuming the respondent would have reported it in line with probability laws. This latter approach was taken by Attanasio et al. (2005), who decided to split their sample randomly after which half were asked the probability that the outcome of interest (future income) would be between the minimum and the midpoint while the other half were asked the probability that the expected outcome would be between the midpoint and the maximum. They then test whether, on average, the reported probabilities sum to one. Without dropping observations that reported probabilities of zero and one, they do not find this to be the case. It is difficult to assess what drives such inconsistencies. Potential explanations include measurement error in probabilities, misreported thresholds, or respondents that do not understand the questions well. In Appendix F we provide some evidence that the latter explanation is unlikely because different reporting errors do not correlate with respondent characteristics, such as their education.

3.3.2. Fitting a Subjective Distribution of Future Enterprise Returns. We use the expectation information described above, and in particular the reported probabilities,

18. Dominitz and Manski (1997) and Attanasio and Augsburg (2016) use similar questions (on household income) in a developed and developing country context, respectively. While these studies ask respondents about four and three thresholds, respectively, the use of more than one threshold is rare in a developing country context and we therefore also only used one. 
to fit a respondent-specific subjective distribution of future entrepreneurial returns. We then compute various moments to be used in the analysis. Following Attanasio et al. (2005) and Attanasio and Augsburg (2016), we assume a piece-wise uniform probability distribution. That is, we assume that the density is a constant for values of the return below the midpoint reported by respondents and a different constant for values above the midpoint, where the two constants are determined by the probability of being below (or above). We focus on the mean and standard deviation of this distribution. We could have used a more complicated distribution function, but our single point of the cumulative distribution function does not allow us to determine which distribution best fits the shape of respondents' expected future enterprise returns.

Table 3 presents cross-sectional statistics for the main return moments at the individual (columns 1 and 2) and village level (columns 3 and 4). The average expected return is USD 2,308 in our sample. The second row shows the standard deviation. Being able to use the second moment of the subjective income distribution is particularly interesting in our setting as it reflects individual uncertainty. Without the expectation data, one would be forced to use sectional variability of actual returns as a proxy for uncertainty. As highlighted by Attanasio and Augsburg (2016), this is legitimate "only under very stringent assumptions, as the cross-sectional variability of actual revenues reflects both intrinsic heterogeneity among different individuals and different realisations of random shocks drawn from a similar distribution. Only the latter represents true uncertainty".

The mean of the standard deviation of the subjective return distribution is USD 381. This is much lower than the cross-sectional uncertainty of realised returns in the year prior to the baseline survey (USD 1,600; unreported). Whether the realised risk indeed ended up this low is of course another matter. Important in the context of this study is that we capture the ex ante perceptions of the respondents.

TABLE 3. Moments of the subjective distribution of entrepreneurial returns.

\begin{tabular}{lcccccc}
\hline Outcome & \multicolumn{2}{c}{ Individual level } & & \multicolumn{2}{c}{ Village level } \\
\cline { 2 - 3 } \cline { 6 - 7 } & mean & s.d. & & mean & s.d \\
\cline { 2 - 3 } \cline { 5 - 6 } & $(1)$ & $(2)$ & & $(3)$ & $(4)$ \\
\hline Average expected returns (USD) & 2,308 & 4,270 & & 2,292 & 1,214 \\
Standard deviation expected returns (USD) & 381 & 934 & & 382 & 235 \\
Coefficient of variation & 0.163 & & 0.033 & & 0.166 & 0.030 \\
\hline
\end{tabular}

Notes: This table provides summary statistics for the main measure of subjective investment risk-the coefficient of variation-and its components. The first (last) two columns give statistics calculated at the individual (village) level.

The third line in Table 3 shows that the coefficient of variation-the standard deviation of expected revenues normalised by the mean expected revenue-is 0.16 on average. This is the main variable we use in our empirical analysis, either at the individual level or aggregated by village (our results are robust to defining risk 
either way) 19 Note that the variability of the coefficient of variation across villages is basically the same as the variability of the same measure at the individual level. There is thus not much variability within villages.

We consider the risk measure aggregated at the village level for two reasons. First and foremost, we feel that the available measures might be affected by measurement error. Averaging at the village level is equivalent to using village-level dummies as instruments and, therefore, to using only the variation across villages in the mean and variance of returns to identify their effect on loan take-up. This is analogous to assuming that projects available in a village are homogeneous in terms of their return 20

Second, the survey only asked about expected investment returns for those women who intended to invest the loan into a business. The information is therefore missing for the $17 \%$ of the sample that planned to use the loan for consumption expenditures (including education and health). In our baseline regressions, we use the full respondent sample including those that indicated that they would use the loan (partially) for consumption. To do so, we impute the individual-level expectations data in four steps. We first run a probit regression of whether the expected risk measure is missing or not, using village dummies, interviewer dummies and covariates as explanatory variables. We then compute the inverse Mill's ratio and in a next step regress the individual risk measure on village dummies, the Mill's ratio and covariates. Lastly, we save the coefficients and impute expected risk. All our results also hold when we exclude these (partial) consumers as can be seen in Table 9 in Section 4.4.

\section{Empirical Findings}

Whilst our focus is to study how the demand for microcredit depends on whether a lender offers joint or individual-liability contracts and on the perceived riskiness of prospective investment projects, we organise the presentation of our empirical results around the predictions of our theoretical model, which is a useful tool to interpret our findings. Although our sample was pre-screened and included only women that had expressed an initial interest in taking a loan, we do observe substantial heterogeneity in loan demand and take-up.

19. The summary statistics for the village-level and the individual-level coefficient of variation in Table 2 differ slightly from those in Table 3 . This is because Table 2 analyses balance across the full sample of respondents that were interviewed both at baseline and at endline. We then compare respondents in the control villages with those in individual-liability treatment villages and, separately, with those in jointliability treatment villages. The sample in Table 3 is different as the control villages are no longer present and the sample is slightly smaller due to the fact that we match the survey data with administrative data of our implementing partner.

20. In Table C.1 in Appendix C, we regress village risk on various village characteristics. Perceived investment uncertainty is higher in villages that recently experienced a crop disaster; where more people lost their job over the last year; where households have more dependents (children younger than 16 and the elderly); where dairy or felt production is a key local industry (vulnerable to weather shocks); where fewer people are Buddhist (indicating a heterogeneous ethnic composition as Buddhism is the main religion in Mongolia); and that are further from the province centre (a measure of access to services). 


\subsection{Liability Structure and Loan Applications}

Proposition 3 above states that, under some mild and plausible conditions on the value of access to future loans, loan demand will be higher under joint liability than under individual liability. In Table 4, we test this hypothesis on the basis of a sample of all women who were interviewed both at baseline and at endline and that had access to either individual or to joint-liability loans (depending on which of these two treatments had been randomly assigned to their village).

Due to the village-level randomisation, the potential borrowers in the joint and individual-liability villages are very similar along a large number of observable characteristics (Table 1). They also do not differ in terms of their risk aversion ( $p$-value: 0.33 ) or our subjective measure of investment risk (p-value: 0.21 ). Our full sample at baseline consisted of 1,148 women, out of which 849 (299) were based in treatment (control) villages. The sample used in Table 4 is slightly smaller due to a few missing observations.

As our dependent variable, we want a measure that reflects decisions by potential borrowers (that is, credit demand) and that is not polluted by loan-officer behaviour (credit supply). The model itself suggests that group members aim to bail each other out if $K$ is valued high enough. This implies that loan officers might be slightly more lenient in granting loans to riskier clients in joint-liability villages because of this mutual insurance effect. To purge our dependent variable from any such effects, we use information collected as part of the follow-up household survey. Respondents were asked whether they had applied for a loan with the lender during the experiment and, if so, whether this loan was granted or not. In case the loan was granted, the respondent was asked whether she accepted the loan offer or not. The outcome variable in Table 4 is Applied for loan: a dummy variable that is " 1 " if the respondent applied for a loan at our implementing partner (XacBank) and she accepted the loan offer if she received one; and " 0 " otherwise.

Out of the total population of potential borrowers in the 30 treatment villages, $64 \%$ initially applied for a loan $59.3 \%$ in individual-liability villages and $68.1 \%$ in jointliability villages) and $50.5 \%$ ended up borrowing (44.1\% in individual-liability villages and $57.4 \%$ in joint-liability villages). Of the women that did not borrow, most were rejected by the lender and we classify these rejected respondents as loan applicants (their demand for credit was not met by a supply; dummy is "1"). However, 32 women did not borrow because they received but then rejected a loan offer. We classify this latter group as non-applicants (dummy is " 0 ") 21

We can now estimate a probit model for the probability that a respondent applied for a loan with the lender. We are interested in the coefficient for Joint liability,

21. For denied loan applicants we do not know whether they would have accepted the loan offer, had they received one, and this might cause some selection bias. Yet, when we code these 32 women instead as applicants, our findings are virtually unchanged (results available upon request). 
TABLE 4. Liability structure and loan applications.

\begin{tabular}{lccc}
\hline & \multicolumn{3}{c}{ Outcome: Applied for loan } \\
\cline { 2 - 4 } & $(1)$ & $(2)$ & $(3)$ \\
\hline Joint Liability (JL) & $0.110^{*}$ & $0.115^{*}$ & $0.108^{*}$ \\
& $(0.086)$ & $(0.070)$ & $(0.070)$ \\
\hline Household covariates & No & Yes & Yes \\
Province FE & No & No & Yes \\
Observations & 836 & 829 & 829 \\
\hline
\end{tabular}

Notes: This table shows probit regressions to estimate the relationship between the microcredit liability structure offered to potential borrowers and loan take-up. Coefficients are marginal effects. Robust standard errors clustered at the village level are shown in parentheses. Covariates included in columns (2) and (3) are: indicator variables whether the household head has high education and is married, his/her age and age squared, whether the household includes at least one member above the age of 60 and below the age of 16, and whether the household is Buddhist and Hahl. We also include information on the household's economic status (whether the dwelling is owned, whether they own a fence, well, vehicle, tools, animals, the value of assets) and indicators whether certain shocks were experienced in the last year (crop disaster, illness, jobloss, death). We finally account for whether the household had debt outstanding and the number of loans. The loss in observations in these two columns is due to missing covariate information. $*, * *, * *$ indicates significance at the 10,5 and 1 percent level.

an indicator of whether the potential borrower was based in a joint-liability rather than an individual-liability treatment village. The first column of Table 4 presents a parsimonious specification while the second column also includes household-level covariates. The third column adds province fixed effects. Standard errors are clustered at the village level. Since we have 30 villages in total (15 individual-liability and 15 joint-liability treatment villages), we also ran linear versions of these regressions so that we can use the wild cluster bootstrap-t procedure in light of the relatively small number of clusters (Cameron et al. (2008)). This does not affect the significance level of our results (as can be seen by the + signs next to the standard errors in robustness Table 7 in Section 4.4.).

Across all three specifications, and in line with our Proposition 3, the application probability is about 11 percentage points higher in the joint-liability villages (this difference is significant at the $10 \%$ level). Most household-level covariates are not strongly correlated with take-up. Households that at baseline owned a well, fence or tools and machinery had a higher probability of getting a loan, either because they are less poor or because they could use these items as collateral. Importantly, these household-level determinants are very similar across both types of treatment villages. In Table D. 1 in Appendix D we show that there are virtually no differences across both village types in terms of various observable characteristics of those that decide to take up loans.

\subsection{Investment Risk, Liability Structure and Loan Applications}

When risk-averse individuals make investment choices, they consider not only the mean expected return of a project but also its risk. In the context of our model, 
Propositions 2 and 4 focus on how changes in project risk, as measured by the variance of its expected returns, affect loan take-up under the two different lending contracts.

We use our preferred measure of perceived project risk, the coefficient of variation of expected investment returns, to study the relationship between risk and loan take-up. As discussed above, we either average the coefficient of variation at the village level or measure it at the individual level. We then exploit the variability of this measure across individuals and villages to identify the relationship between contractual arrangements, risk and loan demand.

TABLE 5. Investment risk, liability structure and loan applications.

\begin{tabular}{|c|c|c|c|c|}
\hline & \multicolumn{2}{|c|}{ Village-level risk } & \multicolumn{2}{|c|}{ Individual-level risk } \\
\hline & (1) & (2) & (3) & (4) \\
\hline Joint Liability (JL) & $\begin{array}{c}-0.554^{* * *} \\
(-2.70)\end{array}$ & $\begin{array}{c}-0.606^{* * *} \\
(-2.92)\end{array}$ & $\begin{array}{c}0.0787^{*} \\
(1.82)\end{array}$ & $\begin{array}{c}0.0700 \\
(1.48)\end{array}$ \\
\hline Investment risk, $\mathrm{CV}$ & $\begin{array}{c}-3.802^{* * *} \\
(-2.72)\end{array}$ & $\begin{array}{c}-3.711^{* * *} \\
(-2.62)\end{array}$ & $\begin{array}{c}-4.570^{* * *} \\
(-3.28)\end{array}$ & $\begin{array}{c}-4.578^{* * *} \\
(-3.21)\end{array}$ \\
\hline $\mathrm{JL} *$ Investment Risk & $\begin{array}{c}4.514^{* * *} \\
(2.67)\end{array}$ & $\begin{array}{c}4.852^{* * *} \\
(2.70)\end{array}$ & $\begin{array}{c}5.355^{* * *} \\
(4.37)\end{array}$ & $\begin{array}{c}5.820^{* * *} \\
(4.77)\end{array}$ \\
\hline Average expected return (ER) & & $\begin{array}{c}0.0969 \\
(0.73)\end{array}$ & & $\begin{array}{l}0.140 \\
(1.42)\end{array}$ \\
\hline $\mathrm{JL} * \mathrm{ER}$ & & $\begin{array}{c}-0.0473 \\
(-0.33)\end{array}$ & & $\begin{array}{c}-0.111^{*} \\
(-1.74)\end{array}$ \\
\hline Household covariates & Yes & Yes & Yes & Yes \\
\hline Province FE & Yes & Yes & Yes & Yes \\
\hline$P$-value $(1+\mathrm{JL}) *$ Risk $=0$ & 0.687 & 0.497 & 0.555 & 0.345 \\
\hline Observations & 829 & 829 & 829 & 829 \\
\hline
\end{tabular}

Notes: This table shows probit regressions to estimate the relationship between microcredit liability structure, investment risk and loan demand (applications). In columns 1 and 2 (3 and 4), investment risk is measured at the village (individual) level. Coefficients are marginal effects. Covariates are the same as in Table 4 . Robust standard errors clustered at the village level are shown in parentheses. *,**,*** indicates significance at the 10,5 and 1 percent level.

Table 5 shows the estimates from a probit model where the probability of applying for a loan is a function of the (average) subjective risk measure and its interaction with liability structure. We again control for various household covariates, include province fixed effects, and cluster standard errors at the village level. In this and all subsequent tables with interaction terms, we de-mean the risk and return measures in the interaction terms for ease of interpretation. The coefficients are marginal effects.

The results in Table 5 line-up nicely with the theoretical predictions of our model. In particular, we find that when investment risk is higher - as measured by a high average variance of subjective risk perceptions - the probability of taking up a loan (and presumably engaging in a productive activity) is significantly lower. Potential borrowers that are more uncertain about their future returns appear less willing to 
commit to the fixed repayment schedule of a loan. This also holds true when we control for expected returns (columns 2 and 4).

While the coefficient on the joint-liability dummy is negative and significant when using village-level risk, it is not significantly different from zero when using individual-level risk while controlling for expected returns. Moreover, the interaction term between joint-liability and investment risk is significantly positive. That is, as predicted by Proposition 4, the effect of project risk on loan take-up is muted in villages where joint-liability contracts are offered. This is in line with our hypothesis that the higher take-up in joint-liability villages can be explained by the insurance role that such contracts play 22

Lastly, note that the sum of the two coefficients on risk, which represents the effect of risk in joint-liability villages, is positive but not significantly different from zero (as shown by the row of $p$-values at the bottom of this and all following tables). While we cannot reject the null of a zero effect of risk on loan take up in joint-liability villages, the size of the coefficients suggests that net positive effects lie within the broad confidence intervals. Such a positive effect of risk on loan take up in joint-liability (but not in individual-liability) villages, would be in line with earlier work highlighting that joint liability can encourage risk taking if borrowers expect to be bailed out by co-borrowers (Giné et al. (2010) and Fischer (2013)). We will come back to this when discussing the intensive-margin results in Table 6 below.

\subsection{Investment Risk, Liability Structure and Loan Size}

An interesting follow-up question to consider is whether the liability structure of the microcredit contracts on offer also has an impact on the intensive margin. Are women that are more uncertain about future returns less willing to take out larger loans (conditional on borrowing) and is this effect tempered in joint-liability villages where mutual insurance may reduce the risk associated with higher debt levels?

The Tobit regressions in Table 6 indicate that this is indeed the case. This holds both when we consider the size of the first loan (columns 1-4) or the total amount borrowed during the experiment (columns 5-8). While, conditional on loan take-up, joint-liability loans tend to be smaller than individual-liability ones (cf. Table 2), higher uncertainty about future entrepreneurial performance is associated with considerably smaller loan amounts. This holds regardless of whether we measure investment risk at the individual or at the village level. Importantly, the interaction term between investment risk and joint liability is consistently positive and large: borrowers that face higher investment risk felt comfortable with borrowing more in joint-liability than in individual-liability villages, all else equal. This holds both when we measure loan take-up by the size of the first loan or by the total amount borrowed and also when we control for average

22. When we conduct an F-test for the joint significance of the joint-liability dummy, the coefficient of variation, and their interaction term, we can reject the null of no joint significance in all four columns ( $p$-value is 0.00 in each case). 
expected investment returns and their interaction with the liability structure on offer (even columns).

Note that the p-values at the bottom of columns 5-8 of Table 6 indicate that the total amount borrowed for risky projects tends to be higher in joint-liability villages. That is, groups that start relatively risky projects expand their total borrowing more in joint-liability villages. This may also be one of the reasons why we find somewhat higher impacts on food and total consumption in these villages in the associated RCT (Attanasio et al., 2015). Importantly, recall that we do not find any differences in repayment performance between both types of villages. That is, the faster scaling up of risky projects in joint-liability villages does not come at the expense of higher default rates. Apparently, excessive risk taking is prevented by a credible threat of ex post social sanctions and/or effective ex ante assortative matching (cf. Appendix A). Our interpretation is therefore a benign one: joint liability appears to be an effective mechanism to overcome unwarranted risk aversion among at least some borrowers who have access to risky but potentially profitable (and scalable) investments.

Lastly, the results also indicate that joint-liability loans are smaller than individualliability ones. Informal conversations with loan officers indicated that some of the joint-liability clients started joint projects, leading to smaller loans per person. This feature does not appear in the model, and would be problematic because the returns to different individuals would be perfectly correlated, removing the insurance motive for joint liability. However, the typical group has more than two clients and, therefore, even when joint projects are started, more than one project. This provides the scope for insurance and the differential effect we document of risk on loan take-up and loan size. 
TABLE 6. Liability structure, investment risk and loan size.

\begin{tabular}{|c|c|c|c|c|c|c|c|c|}
\hline & \multicolumn{4}{|c|}{ Outcome: Size of first loan } & \multicolumn{4}{|c|}{ Outcome: Total amount borrowed } \\
\hline & \multicolumn{2}{|c|}{ Village-level risk } & \multicolumn{2}{|c|}{ Individual-level risk } & \multicolumn{2}{|c|}{ Village-level risk } & \multicolumn{2}{|c|}{ Individual-level risk } \\
\hline & (1) & (2) & (3) & (4) & (5) & (6) & (7) & (8) \\
\hline Joint Liability (JL) & $\begin{array}{c}-1139 * * * \\
(-3.02)\end{array}$ & $\begin{array}{c}-1100^{* * *} \\
(-2.85)\end{array}$ & $\begin{array}{l}-102.0^{*} \\
(-1.83)\end{array}$ & $\begin{array}{l}-98.22^{*} \\
(-1.80)\end{array}$ & $\begin{array}{c}-1821^{* * *} \\
(-3.17)\end{array}$ & $\begin{array}{c}-1764.0^{* * *} \\
(-2.94)\end{array}$ & $\begin{array}{l}-35.47 \\
(-0.41)\end{array}$ & $\begin{array}{l}-32.87 \\
(-0.38)\end{array}$ \\
\hline Investment risk, $\mathrm{CV}$ & $\begin{array}{c}-4104 * * * \\
(-2.72)\end{array}$ & $\begin{array}{c}-4220 * * * \\
(-2.83)\end{array}$ & $\begin{array}{c}-4590 * * * \\
(-2.84)\end{array}$ & $\begin{array}{c}-4685^{* * *} \\
(-2.91)\end{array}$ & $\begin{array}{c}-6046^{* *} \\
(-2.43)\end{array}$ & $\begin{array}{c}-6018^{* *} \\
(-2.42)\end{array}$ & $\begin{array}{c}-6590 * * * \\
(-2.73)\end{array}$ & $\begin{array}{c}-6666^{* * * *} \\
(-2.70)\end{array}$ \\
\hline $\mathrm{JL} *$ Investment Risk & $\begin{array}{c}6854^{* * *} \\
(3.06)\end{array}$ & $\begin{array}{c}6679^{* * *} \\
(2.82)\end{array}$ & $\begin{array}{c}6359^{* * *} \\
(3.70)\end{array}$ & $\begin{array}{c}6465^{* * *} \\
(3.76)\end{array}$ & $\begin{array}{c}11712^{* * *} \\
(3.35)\end{array}$ & $\begin{array}{c}11370.5^{* * *} \\
(3.07)\end{array}$ & $\begin{array}{c}11578^{* * *} * \\
(4.50)\end{array}$ & $\begin{array}{c}11661^{* * *} \\
(4.46)\end{array}$ \\
\hline Av. expected return (ER) & & $\begin{array}{l}-68.00 \\
(-0.47)\end{array}$ & & $\begin{array}{l}-43.74 \\
(-0.52)\end{array}$ & & $\begin{array}{l}-60.34 \\
(-0.26)\end{array}$ & & $\begin{array}{l}-32.39 \\
(-0.26)\end{array}$ \\
\hline $\mathrm{JL} * \mathrm{ER}$ & & $\begin{array}{l}22.06 \\
(0.15)\end{array}$ & & $\begin{array}{l}-3.060 \\
(-0.05)\end{array}$ & & $\begin{array}{l}66.97 \\
(0.29)\end{array}$ & & $\begin{array}{l}-2.554 \\
(-0.03)\end{array}$ \\
\hline Household covariates & Yes & Yes & Yes & Yes & Yes & Yes & Yes & Yes \\
\hline Province FE & Yes & Yes & Yes & Yes & Yes & Yes & Yes & Yes \\
\hline$P$-value $(1+\mathrm{JL}) *$ Risk $=0$ & 0.155 & 0.224 & 0.231 & 0.216 & 0.063 & 0.086 & 0.027 & 0.023 \\
\hline $\mathrm{N}$ & 829 & 829 & 829 & 829 & 829 & 829 & 829 & 829 \\
\hline
\end{tabular}

Notes: This table shows left-censored (at 0 ) tobit regressions to estimate the relationship between the microcredit liability structure offered to potential borrowers, investment risk and the loan amount in US\$. In columns 1-4 the outcome variable is the size of the first loan and in columns 5-8 the total amount borrowed over the period of the experiment. In columns 1, 2, 5, 6 investment risk is aggregated at the village level, in columns 3, 4, 7, 8 at the individual level. Robust standard errors clustered at the village level are shown in parentheses. Covariates are the same as in Table 4. *,**,*** indicates significance at the 10, 5 and 1 percent level.

\subsection{Robustness}

In this section, we submit our baseline findings to a number of robustness tests. In Table 7, we first run linear probability models instead of probit regressions. The estimated marginal effects change only slightly and the significance levels remain the same overall, which is reassuring. This is the case in our baseline regressions without investment risk (columns 1-3); when we measure investment risk at the village level (columns 4-5) and when we measure investment risk at the individual level (columns 67). In each case, the interaction between Investment risk and Joint liability also remains significant when we use the wild cluster bootstrap-t procedure (Cameron et al. (2008)).

Next, in Table 8, we replace the coefficient of variation, a risk variable that requires an additional functional-form assumption, with a simpler alternative risk measure, the range of variation (the difference between the minimum and maximum expected entrepreneurial returns). The results again remain qualitatively unchanged, both when we estimate probit regressions (columns 1 and 2) and when we use linear regressions (columns 3 and 4).

In Table 9, we exclude respondents who during the baseline survey indicated that they did not intend to use future credit for any entrepreneurial purpose. In the analysis so far, we included these respondents while imputing the values for the entrepreneurial risk measures. We prefer our baseline specification because all respondents could effectively use resources for an entrepreneurial activity and because dropping part of the sample might introduce selection issues. However, after dropping this $17 \%$ 
TABLE 7. Robustness - Linear regressions.

\begin{tabular}{|c|c|c|c|c|c|c|c|}
\hline & \multicolumn{3}{|c|}{ Applied } & \multicolumn{2}{|c|}{ Applied, VL } & \multicolumn{2}{|c|}{ Applied, IL } \\
\hline & (1) & (2) & (3) & (4) & (5) & (6) & (7) \\
\hline Joint Liability (JL) & $\begin{array}{l}0.110^{*} \\
(1.72)^{+}\end{array}$ & $\begin{array}{c}0.111^{*} \\
(1.77)^{+}\end{array}$ & $\begin{array}{c}0.0976^{*} \\
(1.72)\end{array}$ & $\begin{array}{c}-0.527^{* *} \\
(-2.08)\end{array}$ & $\begin{array}{c}-0.605^{* *} \\
(-2.25)\end{array}$ & $\begin{array}{l}0.0645 \\
(1.62)\end{array}$ & $\begin{array}{l}0.0584 \\
(1.33)\end{array}$ \\
\hline Investment risk, $\mathrm{CV}$ & & & & $\begin{array}{c}-3.433^{* *} \\
(-2.63)^{+++}\end{array}$ & $\begin{array}{c}-3.381^{* *} \\
(-2.54)^{++}\end{array}$ & $\begin{array}{c}-4.032^{* * *} \\
(-3.27)^{+++}\end{array}$ & $\begin{array}{c}-4.022^{* * *} \\
(-3.19)^{+++}\end{array}$ \\
\hline $\mathrm{JL} *$ Investment Risk & & & & $\begin{array}{l}3.957^{* *} \\
(2.51)^{+}\end{array}$ & $\begin{array}{l}4.380^{* *} \\
(2.60)^{+}\end{array}$ & $\begin{array}{c}4.582^{* * *} \\
(4.32)^{+++}\end{array}$ & $\begin{array}{c}4.972^{* * *} \\
(4.64)^{+++}\end{array}$ \\
\hline Avg. expected return (ER) & & & & & $\begin{array}{l}0.101 \\
(0.83)\end{array}$ & & $\begin{array}{l}0.120 \\
(1.36)\end{array}$ \\
\hline $\mathrm{JL} * \mathrm{ER}$ & & & & & $\begin{array}{c}-0.0711 \\
(-0.53)\end{array}$ & & $\begin{array}{l}-0.105^{*} \\
(-1.85)\end{array}$ \\
\hline Household covariates & No & Yes & Yes & Yes & Yes & Yes & Yes \\
\hline Province FE & No & No & Yes & Yes & Yes & Yes & Yes \\
\hline$P$-value $(1+\mathrm{JL}) *$ Risk $=0$ & & & & 0.747 & 0.519 & 0.635 & 0.402 \\
\hline $\mathrm{N}$ & 836 & 829 & 829 & 829 & 829 & 829 & 829 \\
\hline
\end{tabular}

Notes: This table provides robustness tests, using a linear regression approach instead of probit regressions to estimate in columns 1-3 the relationship between microcredit liability structure and loan demand (application) and in columns 4-7 the relationship between microcredit liability structure, investment risk and loan demand (applications). In columns 4, 5 investment risk is measured at the village level, in columns 6, 7 at the individual level. Robust standard errors clustered at the village level are shown in parentheses. Covariates are the same as in Table 4. *, **, *** indicates significance at the 10,5 and 1 percent level. ${ }^{+},++,+++$indicates significance using the wild cluster bootstrap-t procedure at the 10,5 and 1 percent level.

of the sample, our results continue to hold: higher risk is associated with fewer loan applications but this effect is muted where microcredit is offered with joint liability.

In Table E. 1 in Appendix E, we replicate our baseline finding from Table 5 in the first column. One may worry that other covariates correlate with investment risk and this may drive part of the interaction effect between Investment risk and Joint Liability. To analyse whether this is the case, we add a number of additional covariates and their interactions with Joint liability in the following columns.

In column 2, we add an indicator for whether the household head is highly educated or not and interact this variable with Joint liability. In column 3, we do the same with an indicator whether the household had loans outstanding at baseline or not. Some borrowers already had a small loan at the start of the experiment (typically some form of consumer credit) and this variable turned out not to be balanced at baseline. The results show that participants that already had some credit were also more likely to borrow for business purposes during the experiment. In column 4, we add an indicator of whether the household owned an enterprise at baseline while in column 5 we add a measure of risk aversion (we count the number of "safe" choices that a borrower picked when going through a set of five paired lottery choices, as in Holt and Laury (2002)).

In all cases, we continue to find a negative relationship between investment risk and demand for credit and this relationship is muted in joint-liability treatment villages. This is also the case when we add the additional interaction terms (Highly educated, Loans at baseline, Enterprise at baseline, Risk aversion) all at the same 
TABLE 8. Robustness checks - Range risk measure.

\begin{tabular}{|c|c|c|c|c|}
\hline & \multicolumn{2}{|c|}{ Probit } & \multicolumn{2}{|c|}{ Linreg } \\
\hline & (1) & (2) & (3) & (4) \\
\hline Joint Liability (JL) & $\begin{array}{c}0.0861^{*} \\
(1.70)\end{array}$ & $\begin{array}{l}0.0578 \\
(1.14)\end{array}$ & $\begin{array}{l}0.0724 \\
(1.54)\end{array}$ & $\begin{array}{l}0.0475 \\
(1.00)\end{array}$ \\
\hline Investment risk, range & $\begin{array}{c}-0.651^{* * *} \\
(-2.59)\end{array}$ & $\begin{array}{c}-0.728^{* *} \\
(-2.52)\end{array}$ & $\begin{array}{c}-0.590^{* *} \\
(-2.52)\end{array}$ & $\begin{array}{c}-0.673^{* *} \\
(-2.45)\end{array}$ \\
\hline $\mathrm{JL} *$ Investment Risk & $\begin{array}{c}0.687^{* *} \\
(2.13)\end{array}$ & $\begin{array}{c}0.777^{* *} \\
(2.31)\end{array}$ & $\begin{array}{c}0.609^{*} \\
(1.96)\end{array}$ & $\begin{array}{c}0.719^{* *} \\
(2.23)\end{array}$ \\
\hline Average expected return (ER) & & $\begin{array}{l}0.150 \\
(1.10)\end{array}$ & & $\begin{array}{l}0.150 \\
(1.18)\end{array}$ \\
\hline $\mathrm{JL} * \mathrm{ER}$ & & $\begin{array}{c}-0.0948 \\
(-0.66)\end{array}$ & & $\begin{array}{l}-0.116 \\
(-0.87)\end{array}$ \\
\hline Household covariates & Yes & Yes & Yes & Yes \\
\hline Province FE & Yes & Yes & Yes & Yes \\
\hline$P$-value $(1+\mathrm{JL}) *$ Risk $=0$ & 0.924 & 0.887 & 0.958 & 0.889 \\
\hline $\mathrm{N}$ & 829 & 829 & 829 & 829 \\
\hline
\end{tabular}

Notes: This table provides robustness tests where we measure subjective investment risk as the range between reported minimum and maximum expected returns instead of the coefficient of variation. Columns 1-2 (3-4) report probit (linear) regressions. $p$-values in parentheses, robust standard errors clustered at the village level. Covariates are the same as in Table 4. *,**,*** indicates significance at the 10,5 and 1 percent level.

time (unreported). In sum, including these additional interaction terms does not impact our findings on the role of joint liability and perceived investment risk. Moreover, these covariates do not have a strong independent effect on loan applications, with the exception of Loans at baseline, which increased the likelihood of loan application during the experiment and did so independently of the liability structure that was on offer in a village.

Finally, in Table E.2 in Appendix E, we check whether our results are robust to imposing two restrictions on our subjective expectations data when creating our investment risk measure, the coefficient of variation. As discussed in Section 4.1, so far we have not used any restrictions. In columns 3 and 4, we re-estimate our baseline regressions (repeated for ease of reference in the first two columns) while imposing two restrictions. First, we replace all values where respondents reported probabilities of zero or one with imputed values. Second, we do the same for all respondents whose reported probabilities added up to more than 120 or less than 80 . The results in the left- and right-hand side of Table E. 2 are very similar, indicating that these restrictions have little impact. 
TABLE 9. Robustness: Excluding respondents with non-productive investment intentions.

\begin{tabular}{|c|c|c|c|c|}
\hline & \multicolumn{2}{|c|}{ Village-level risk } & \multicolumn{2}{|c|}{ Individual-level risk } \\
\hline & (1) & (2) & (3) & (4) \\
\hline Joint Liability (JL) & $\begin{array}{c}-0.366^{*} \\
(-1.72)\end{array}$ & $\begin{array}{c}-0.483^{* *} \\
(-2.32)\end{array}$ & $\begin{array}{c}0.0743^{*} \\
(1.73)\end{array}$ & $\begin{array}{l}0.0625 \\
(1.33)\end{array}$ \\
\hline Investment risk, $\mathrm{CV}$ & $\begin{array}{c}-2.899^{* *} \\
(-2.28)\end{array}$ & $\begin{array}{c}-2.899^{* *} \\
(-2.28)\end{array}$ & $\begin{array}{c}-3.016^{* *} \\
(-2.41)\end{array}$ & $\begin{array}{c}-3.068^{* *} \\
(-2.47)\end{array}$ \\
\hline $\mathrm{JL} *$ Investment Risk & $\begin{array}{c}2.979^{*} \\
(1.92)\end{array}$ & $\begin{array}{c}3.677^{* *} \\
(2.25)\end{array}$ & $\begin{array}{c}4.153^{* * *} \\
(3.60)\end{array}$ & $\begin{array}{c}4.821^{* * * *} \\
(4.20)\end{array}$ \\
\hline Average expected return (ER) & & $\begin{array}{l}0.178 \\
(1.13)\end{array}$ & & $\begin{array}{c}0.176^{*} \\
(1.72)\end{array}$ \\
\hline $\mathrm{JL} * \mathrm{ER}$ & & $\begin{array}{l}-0.143 \\
(-0.87)\end{array}$ & & $\begin{array}{c}-0.165^{* *} \\
(-2.52)\end{array}$ \\
\hline Household covariates & Yes & Yes & Yes & Yes \\
\hline Province FE & Yes & Yes & Yes & Yes \\
\hline$P$-value $(1+\mathrm{JL}) *$ Risk $=0$ & 0.960 & 0.602 & 0.315 & 0.100 \\
\hline Observations & 674 & 674 & 674 & 674 \\
\hline
\end{tabular}

Notes: The regressions in this table estimate the relationship between microcredit liability structure, investment risk and loan demand (applications). They are based on a sample that excludes respondents that reported at baseline that they intended to use the loan for consumption purposes. In columns 1 and 2 (3 and 4), investment risk is measured at the village (individual) level. Robust standard errors clustered at the village level are shown in parentheses. Covariates are the same as in Table 4. *,**, *** indicates significance at the 10, 5 and 1 percent level.

\section{Conclusions}

We have analysed the demand for microcredit under different liability arrangements and risk environments. We started out with a theoretical model to show that the demand for joint-liability loans can exceed that for individual-liability loans when risk-averse borrowers value their long-term relationship with the lender. Joint liability then offers a way to diversify risk and to reduce the chance of losing access to future loans.

To perform our analysis, we need a setting with significant cross-sectional variation in investment risk as well as a good measure of individuals' subjective perceptions of this risk. Moreover, we need exogenous variation in the liability structure that is offered to borrowers. We exploit data from a randomised controlled trial in Mongolia that fulfil these requirements and obtain empirical findings that are in line with our model predictions. We first of all observe that individuals that are offered a joint-liability loan are more likely to take up credit than individuals that are offered individual-liability credit. Using novel measures of subjective risk perceptions, we find that - in line with the predictions of the model - the probability of loan take-up is lower in villages where risk is higher. In line with an insurance role of joint-liability contracts, this effect is muted (or even fully offset) in villages where joint-liability loans are available.

The recently published RCTs on the impact of microcredit have made significant progress in understanding the (average) impacts of microcredit. At the same time, this 
evidence has also raised many new questions. We think an interesting research agenda - both from an academic and a practitioners' angle - is to study whether microcredit product design (liability structure, flexible repayment schedules, grace periods etc.) can contribute to higher take-up rates and possibly stronger impacts. An important policy implication of our findings is that product design can be a key determinant of loan take-up and that this may hold true in particular in high-risk environments, which are prevalent in many emerging and developing countries.

In particular, our results suggest that in such risky environments, especially relatively risk-averse borrowers may value the insurance aspect of joint-liability microcredit contracts as it provides them with a form of insurance. While a continuation of the trend towards liability individualisation may therefore be beneficial to less risk averse (for example, relatively wealthy) borrowers, this trend may at the same time gradually exclude poorer and more risk-averse borrowers from the market for formal financial services. Additional research, in which theory and empirical work continue to inform each other - as recently advocated by Fischer and Ghatak (2011) - is necessary to further the debate about the relationship between the design of microcredit contracts and the real-economic impact of microcredit among populations that were previously excluded from formal finance.

A related direction for future research concerns the role of ex ante differentiation among microcredit clients so that microlenders can better target their product offer. Here, explicitly distinguishing between smaller consumption loans versus larger (and longer) entrepreneurial loans may be important, as are better ways to help successful microcredit clients to transition from micro to SME status. Recent empirical research indicates that while the average impacts of access to microcredit may be small, there can be significant positive longer-term effects on business growth and performance for borrowers with a pre-existing enterprise (and thus a demonstrated interest in and ability to conduct a business) ${ }^{23}$ Rigorous empirical research, informed by theory, will be necessary to help microfinance practitioners to gradually move from a cookie-cutter approach towards a more differentiated product offer.

\section{Appendix A: Assortative Matching}

We would like to assess whether group formation in joint-liability villages was characterised by assortative matching. Theory suggests that homogeneous matching may take place based on risk types (Ghatak (1999), Ghatak (2000); Gangopadhyay et al. (2005), Ghatak (2000); Gangopadhyay et al. (2005)). Alternatively, borrowers may match heterogeneously to benefit as much as possible from mutual insurance (Sadoulet (1999)).

We first analyse whether our experimental setting was characterised by selfselection into homogeneous risk groups. To do so, we create borrower-level measures

23. See, e.g., Angelucci et al. (2015); Banerjee et al. (2017); Meager (2016a). 
of risk aversion and subjective project risk. To measure risk aversion, we count the number of "safe" choices that a borrower picked when going through five paired lottery choices (cf. Holt and Laury (2002)). To measure project risk, we use the log difference between the respondent's highest and lowest return estimate for the next year.

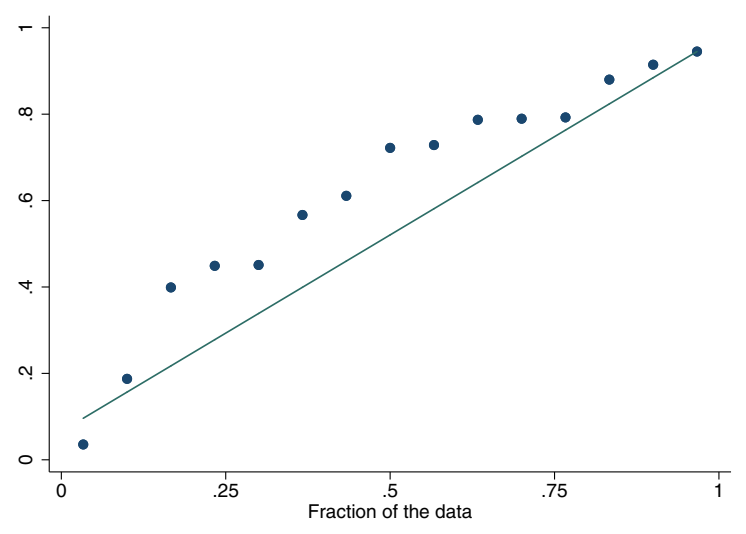

(a) Quantile plot of the village sorting percentile for Number of safe choices.

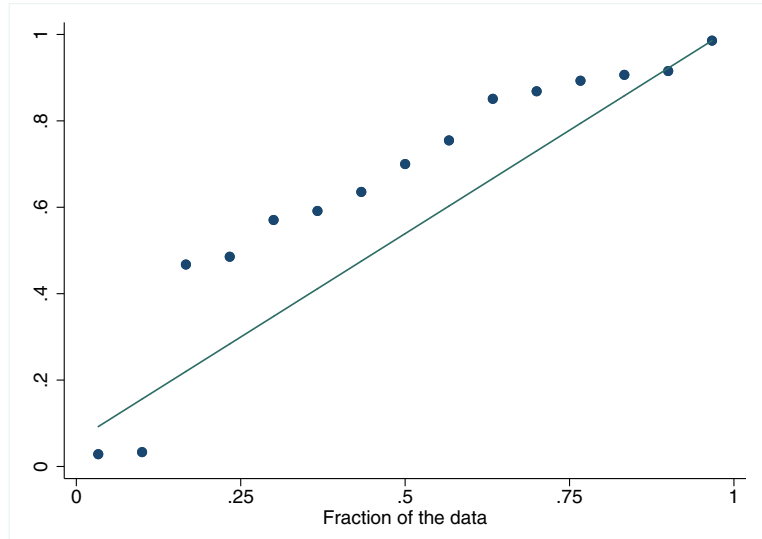

(b) Quantile plot of the village sorting percentile for Range of Revenue.

Figure A.1. Assortative matching in joint-liability villages, by risk. These two graphs plot the default order values of the village sorting percentiles (y-axis) against their cumulative probabilities ( $\mathrm{x}$-axis). The sorting percentile is the percentage of all possible groupings of borrowers in the village that result in a lower value of the variable Between than the one observed. Between is a measure of group homogeneity and higher values indicate more homogeneous groups within a village. In graph (a) individual risk aversion is measured as the number of safe choices the respondent made in a lottery game. In graph (b) individual risk is measured as the difference between the revenue expected in an extremely successful year and the revenue expected in and extremely unsuccessful year. The diagonal represents the random uniform distribution. 
Next, we use these two risk measures to assess whether the observed borrower groups were more homogeneous in terms of risk aversion and borrower risk when compared to all hypothetical borrower configurations (of the same group sizes) that could have been possible in a village but did not materialise in reality (see Figure A.1). To compare the observed configuration with this universe of hypothetical group configurations, we calculate for each configuration the village-level summary measure Between. We do this for both the risk-aversion measure and the project-risk measure. Between is the ratio of the between-group to the overall variance in a village. As a measure of group homogeneity, high values of Between indicate that within-group variance is low.

We then compare how homogeneous the observed grouping of borrowers in a specific village is compared with the possible groupings of the same borrowers in that village. Due to the limited number of hypothetical groupings in a village it is not possible to calculate the exact percentage of possible groupings that would have resulted in a lower Between measure. Instead we calculate a sorting percentile range and report its mean.

For the risk aversion measure, the average village has a mean sorting percentile of 0.62 . This means that, on average, $62 \%$ of all the possible groupings in the jointliability villages would have resulted in a lower Between value than the one observed. That is, the average village is more homogeneous than $62 \%$ of all possible groupings. The median village is more homogeneous than $72 \%$ of all possible groupings. For the income risk measure, we find similar results. Here the mean (median) sorting percentile is $65 \%(70 \%)$. We conclude that it is likely that the endogenous group formation in the 15 joint-liability villages was to some extent characterised by assortative matching.

In a next step, we also assess whether there is evidence of assortative matching based on the respondent's intended loan use at baseline. Our data suggest this is not the case. As with sorting based on risk, we compare the observed configuration with all possible group configurations and calculate for each configuration the village-level measure Between. For the variable that indicates a respondent's intention to fund or setup her own business, the average village has a mean sorting percentile of 0.52 . This means that, on average, $52 \%$ of all the possible groupings in the joint-liability villages would have resulted in a lower Between value than the one observed. The average village is thus more (less) homogeneous than $52 \%$ (48\%) of all possible groupings. For the intention to setup or fund a joint business, these numbers are $49 \%(51 \%)$ and for the intention to use the loan for non-business purposes they are $51 \%(49 \%)$.

Figure A. 2 shows the distribution of the observed sorting percentiles across villages against the uniform distribution. In case of strongly homogeneous groups, we would expect the observed distribution to be above the uniform one. This would indicate that a smaller share of observed villages has a lower sorting percentile than if the distribution was uniform. We do not find strong evidence for this hypothesis. We conclude that it is unlikely that the endogenous group formation in the fifteen joint-liability villages was characterised by assortative matching based on intended loan use. 


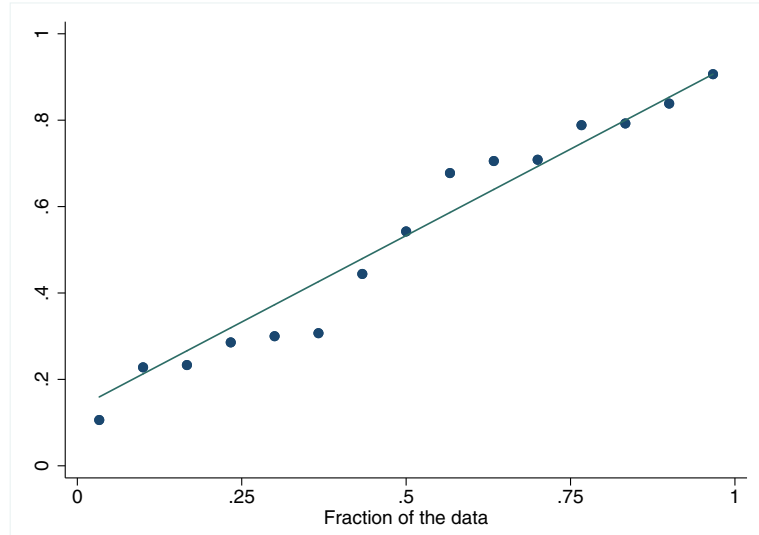

(a) Quantile plot of the village sorting percentile for Intent to use loan for own enterprise.

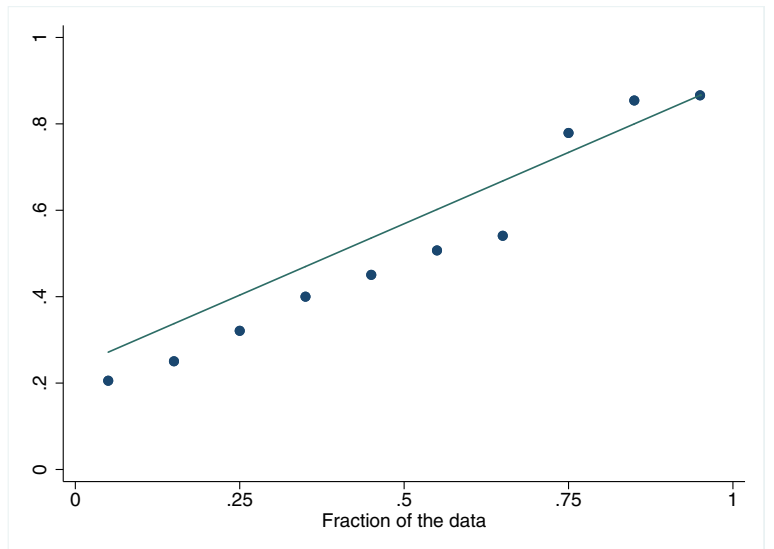

(b) Quantile plot of the village sorting percentile for Intent to use loan for non-business purposes.

FIgure A.2. Assortative matching in joint-liability villages, by intended loan use. These two graphs plot the default order values of the village sorting percentiles (y-axis) against their cumulative probabilities (x-axis). The sorting percentile is the percentage of all possible groupings of borrowers in the village that result in a lower value of the variable Between than the one observed. Between is a measure of group homogeneity and higher values indicate more homogeneous groups within a village. Graph (a) assesses homogeneity in terms of the percentage of respondents that indicated at baseline that they intended to use a loan for their own enterprise. Graph (b) be assesses homogeneity in terms of the percentage of respondents that indicated at baseline that they intended to use a loan for non-business purposes. The diagonal represents the random uniform distribution. 


\section{Appendix B: Proof of Propositions 2, 3 and 4}

\section{Proof of Proposition 2}

Consider a new distribution of $R^{L}, g\left(R^{L}\right)$ (with cdf $G\left(R^{L}\right)$ ), which is a mean preserving spread of $f\left(R^{L}\right)$, in the sense that probability weight has been taken from the centre of $f$ and moved to the tails. We assume that following this increase in riskiness $G(A)>F(A) \sqrt{24}$, and that it only affects one of the individuals in the joint-liability case (individual 1 ). The discontinuity in our utility function around the repayment threshold (for individual $1, R^{L}=A$ under the individual-liability contract; $R^{L}=2 A-\tilde{R^{L}}$ under the joint-liability contract) means that second-order stochastic dominance does not ensure that the Proposition holds in general. For instance, consider a case under the individual-liability contract where $K$ is relatively small and $A$ is close to the mean. In that case, and if we assume that $G(A)>F(A)$, expected utility may potentially increase as a result of an increased likelihood that the borrower will be able to forego giving up $R^{B} B$ upon reaching the threshold, the gains to which $(K)$ fail to offset the loss.

As already mentioned, $K$ is nevertheless likely to be large as it represents all future potential gains from having access to credit. We therefore show under what conditions on $K$ Proposition 2 holds true. To show that, for a given mean of the risky project, the fraction of individuals that apply for a loan is decreasing in the variance of the project, we need to show in the individual-liability case that:

$$
\begin{gathered}
\int_{0}^{A} u\left(y+R^{L}(D+B)\right) f\left(R^{L}\right) d R^{L}+\int_{A}^{\overline{R^{L}}}\left[u\left(y+R^{L}(D+B)-R^{B} B\right)+K\right] f\left(R^{L}\right) d R^{L} \\
>\int_{0}^{A} u\left(y+R^{L}(D+B)\right) g\left(R^{L}\right) d R^{L}+\int_{A}^{\overline{R^{L}}}\left[u\left(y+R^{L}(D+B)-R^{B} B\right)+K\right] g\left(R^{L}\right) d R^{L}
\end{gathered}
$$

This can be written as a condition on $\mathrm{K}$ :

$$
K\left\{[1-F(A)]-[1-G(A)]>E_{G}\left[u^{\text {indiv.* }}\right]-E_{F}\left[u^{\text {indiv.* }}\right]\right.
$$

where $E_{F}\left[u^{\text {indiv.* }}\right]$ and $E_{G}\left[u^{\text {indiv.* }}\right]$ are analogous to the object (3) in the layout of Proposition 3 in the main text, with the subscripts denoting the distributions of $R^{L}$ the expectations are taken over $\left(g\left(R^{L}\right)\right.$ or $\left.f\left(R^{L}\right)\right)$. The right-hand side of this condition, $E_{G}\left[u^{\text {indiv.* }}\right]-E_{F}\left[u^{\text {indiv.*}}\right]$, is decreasing in $E\left[R^{L}\right]$ for given $A$.

The left-hand side of this condition is the change in expected utility that arises due to the change in probability that the relationship with the lender is maintained - the probability that $R^{L}=A$ - following a shift in the distribution of the return on the risky asset from $f$ to $g$. In the case we consider above, where $f$ is symmetric and the spread shifts weight evenly to each tail and $A<E\left[R^{L}\right]$, this expression would be

24. Given that we assume $A<E\left[R^{L}\right]$, this is the case if $f$ is a symmetric distribution and the spread is such that weight is moved symmetrically to either tail. 
positive because $G(A)>F(A)$. The right-hand side represents the change in expected utility resulting solely from returns on the risky asset (that is, ignoring the value of maintaining a relationship with the lender, $K$ ). By second-order stochastic dominance, if the utility function was a continuous and concave function of $R^{L}$, this expression would be negative.

Because in our model the utility function is discontinuous at the repayment threshold (when making the repayment, at the margin individuals lose $R^{B} B$ in returns but gain $K$ in utils), the right-hand side could be positive if expected returns are close to $A$. In such a case, people may value the increase in risk because it makes it less likely that they will reach the repayment threshold, and it is thus less likely they lose $R^{B} B$ in returns. The magnitude of the right-hand side will depend on the location of $A$ with respect to $E\left[R^{L}\right]$ as well as the concavity of the utility function. Thus the overall condition says that for the spread to be expected-utility decreasing, the expected-utility losses resulting from the reduced likelihood of maintaining a relationship with the lender must be larger than any expected-utility gains that may arise as a result of the reduction in the likelihood of having to make the repayment $R^{B} B$.

A similar condition needs to hold for the joint-liability case:

$K\left\{\int_{0}^{\overline{R^{L}}} \int_{0}^{2 A-R^{L}} g\left(\tilde{R^{L}}\right) d \tilde{R^{L}} g\left(R^{L}\right) d R^{L}-\int_{0}^{\overline{R^{L}}} \int_{0}^{2 A-R^{L}} f\left(\tilde{R^{L}}\right) d \tilde{R^{L}} f\left(R^{L}\right) d R^{L}\right\}>E_{G}\left[u^{j o i n t *}\right]-E_{F}\left[u^{j o i n t *}\right]$

This has an interpretation analogous to the individual-liability case.

\section{Proof of Proposition 3}

Assumption 1 implies that $E\left[u^{\text {joint }}\right]>E\left[u^{\text {indiv }}\right]$. This can be seen from a consideration of the expected utilities. For Proposition 3 to hold, we require that:

$$
\begin{aligned}
& \int_{0}^{2 A} \int_{0}^{2 A-R^{L}} u\left(y+R^{L}(D+B)\right) f\left(\tilde{R^{L}}\right) d \tilde{R^{L}} f\left(R^{L}\right) d R^{L} \\
& +\int_{0}^{A} \int_{2 A-R^{L}}^{\overline{R^{L}}}[u(y)+K] f\left(\tilde{R^{L}}\right) d \tilde{R^{L}} f\left(R^{L}\right) d R^{L} \\
& +\int_{A}^{\overline{R^{L}}} \int_{2 A-R^{L}}^{A}\left[u\left(y+\left(R^{L}+\tilde{R^{L}}\right)(D+B)-2 R^{B} B\right)+K\right] f\left(\tilde{R^{L}}\right) d \tilde{R^{L}} f\left(R^{L}\right) d R^{L} \\
& \quad+\int_{A}^{R^{L}} \int_{A}^{R^{L}}\left[u\left(y+R^{L}(D+B)-R^{B} B\right)+K\right] f\left(\tilde{R^{L}}\right) d \tilde{R^{L}} f\left(R^{L}\right) d R^{L} \quad> \\
& \int_{0}^{A} u\left(y+R^{L}(D+B)\right) f\left(R^{L}\right) d R^{L}+\int_{A}\left[u\left(y+R^{L}(D+B)-R^{B} B\right)+K\right] f\left(R^{L}\right) d R^{L}
\end{aligned}
$$

Rearranging so that all of the terms containing $K$ are on one side, one ends up with the condition in Assumption 1. It follows that if Assumption 1 holds, $E\left[u^{\text {joint }}\right]>$ 
$E\left[u^{\text {indiv. }}\right]$ and $u\left(y+R^{s * *} D\right)=U^{G}>U^{I}=u\left(y+R^{s *} D\right)$. This in turn implies that $R^{s * *}>R^{s *}$. Hence there is additional loan take-up by individuals with $R^{s} \in$ $\left(R^{s *}, R^{s * *}\right]$ under the joint-liability contract.

Thus, in order for Propositions 2 and 3 to hold under distribution $f\left(R^{L}\right)$, the condition required on $\mathrm{K}$ is:

$$
\begin{aligned}
K \geq \max ( & \frac{E_{F}\left[u^{i n d i v . *}\right]-E_{F}\left[u^{j o i n t *}\right]}{F(A)-\int_{0}^{\overline{R^{L}}} \int_{0}^{2 A-R^{L}} f\left(\tilde{R^{L}}\right) d \tilde{R^{L}} f\left(R^{L}\right) d R^{L}}, \frac{E_{G}\left[u^{\text {indiv.*}}\right]-E_{F}\left[u^{\text {indiv.*}}\right]}{G(A)-F(A)}, \\
& \left.\frac{E_{G}\left[u^{j o i n t *}\right]-E_{F}\left[u^{j o i n t *}\right]}{\int_{0}^{R^{L}} \int_{0}^{2 A-R^{L}} g\left(\tilde{R^{L}}\right) d \tilde{R^{L}} g\left(R^{L}\right) d R^{L}-\int_{0}^{R^{L}} \int_{0}^{2 A-R^{L}} f\left(\tilde{R^{L}}\right) d \tilde{R^{L}} f\left(R^{L}\right) d R^{L}}\right)
\end{aligned}
$$

Note that we have excluded the object:

$$
\frac{E_{G}\left[u^{\text {indiv.* }}\right]-E_{G}\left[u^{\text {joint* }}\right]}{G(A)-\int_{0}^{\overline{R^{L}}} \int_{0}^{2 A-R^{L}} g\left(\tilde{R^{L}}\right) d \tilde{R}^{L} g\left(R^{L}\right) d R^{L}}
$$

from the right-hand side of the condition. This is because, under Proposition 4, we know that:

$$
\frac{E_{F}\left[u^{\text {indiv.* }}\right]-E_{F}\left[u^{\text {joint* }}\right]}{F(A)-\int_{0}^{\bar{R}^{L}} \int_{0}^{2 A-R^{L}} f\left(\tilde{R^{L}}\right) d \tilde{R^{L}} f\left(R^{L}\right) d R^{L}}>\frac{E_{G}\left[u^{\text {indiv.* }}\right]-E_{G}\left[u^{\text {joint* }}\right]}{G(A)-\int_{0}^{R^{L}} \int_{0}^{2 A-R^{L}} g\left(\tilde{R^{L}}\right) d \tilde{R^{L}} g\left(R^{L}\right) d R^{L}}
$$

Hence it is implicit that $K$ will be large enough to ensure that Proposition 3 holds under both the original distribution and its mean-preserving spread.

\section{Proof of Proposition 4}

Consider a mean-preserving spread of the same kind as the one described in Proposition 2 (that is, one that makes $G(A)>F(A)$ ), and assume that this increase in riskiness only affects one of the individuals in the joint-borrowing partnership (individual 1). Proposition 4 can be seen by considering the cases illustrated in Figure 1 :

Case $1: R^{L} \geq A, \tilde{R}^{L} \geq A$

Case 2: $R^{L} \geq 2 A-\tilde{R}^{L}, \tilde{R}^{L}<A$

Case 3: $R^{L}<A, \tilde{R}^{L} \geq 2 A-R^{L}$

Case 4: $R^{L} \geq A, R^{L} \leq 2 A-\tilde{R^{L}}, \tilde{R}^{L}<A$

Case 5: $R^{L}<A, \tilde{R}^{L} \leq 2 A-R^{L}, \tilde{R}^{L} \geq A$

Case 6: $R^{L}<A, \tilde{R}^{L}<A$

The utilities delivered to individual 1 in each case under the two types of contract, as well as their relative magnitudes given Assumption 2, are laid out below: 


\begin{tabular}{|c|c|c|c|}
\hline Case & Joint Contract Utility & & Individual Contract Utility \\
\hline \hline 1 & $u\left(y+R^{L}(D+B)-R^{B} B\right)+K$ & $=$ & $u\left(y+R^{L}(D+B)-R^{B} B\right)+K$ \\
\hline 2 & $u\left(y+\left(R^{L}+R^{L}\right)(D+B)-2 R^{B} B\right)+K$ & $<$ & $u\left(y+R^{L}(D+B)-R^{B} B\right)+K$ \\
\hline 3 & $u(y)+K$ & $\geq$ & $u\left(y+R^{L}(D+B)\right)$ \\
\hline 4 & $u\left(y+R^{L}(D+B)\right)$ & $<$ & $u\left(y+R^{L}(D+B)-R^{B} B\right)+K$ \\
\hline 5 & $u\left(y+R^{L}(D+B)\right)$ & $=$ & $u\left(y+R^{L}(D+B)\right)$ \\
\hline 6 & $u\left(y+R^{L}(D+B)\right)$ & $=$ & $u\left(y+R^{L}(D+B)\right)$ \\
\hline
\end{tabular}

The effect of this mean-preserving spread is to shift probability weight from cases 1,2 , and 4 to cases 3, 5, and 6. This makes states of the world in which the joint-liability contract is weakly preferred to the individual-liability contract more likely, and states where the individual-liability contract is weakly preferred to the joint-liability contract less likely. This means that under the new distribution $g\left(R^{L}\right)$ we have that:

$$
E_{G}\left[u\left(y+R^{s *} D\right)\right]-E_{G}\left[u\left(y+R^{s * *} D\right)\right]<E_{F}\left[u\left(y+R^{s *} D\right)\right]-E_{F}\left[u\left(y+R^{s * *} D\right)\right]
$$

which is equivalent to:

$$
E_{G}\left[u\left(y+R^{s *} D\right)\right]-E_{F}\left[u\left(y+R^{s *} D\right)\right]<E_{G}\left[u\left(y+R^{s * *} D\right)\right]-E_{F}\left[u\left(y+R^{s * *} D\right)\right]
$$

which is what we needed to show to prove the proposition.

Cases 3, 5, and 6 (where $R^{L}<A$ ) are states of the world where the individual weakly prefers the joint-liability contract. The individual is either "bailed out" by her borrowing partner where she otherwise would have failed to repay if she had been individually liable (case 3 ), thus benefiting from the receipt of $K$ utils; or she receives exactly the same payoff as she would have received under the individualliability contract (cases 5 and 6). In cases where she would be able to repay on her own anyway $\left(R^{L}>A\right)$, she either loses out due to failing to earn enough to "bail out" her partner and repay their total joint liability (case 4); will manage to cover her joint liability but lose out on her total return relative to individual liability because she has to cover her partner's shortfall (case 2); or her utility is the same as it would have been under individual liability (case 1). Thus, by making cases where individual 1 either prefers the joint-liability contract, or is indifferent between joint and individual liability, relatively more likely than cases where the individual-liability contract is preferred (or where she is indifferent between the two), the relative desirability of the joint-liability contract increases. This means that expected utility is falling by a smaller amount, for the given increase in riskiness, under joint liability than under individual liability, which is equivalent to Proposition 4.

\section{Appendix C: Determinants of Village-level Risk}


TABLE C.1. Determinants of village-level risk.

\begin{tabular}{lc}
\hline & Village risk \\
\hline Crop disaster \% & $0.385^{* *}$ \\
Job loss \% & $(0.048)$ \\
& $2.644 *$ \\
Robbery \% & $(0.279)$ \\
& 0.158 \\
Death \% & $(0.124)$ \\
& 0.070 \\
Illness \% & $(0.140)$ \\
& -0.022 \\
Money transfers \% & $(0.61)$ \\
& 0.051 \\
Under 16 & $(0.039)$ \\
Over 60 & $0.196^{* * *}$ \\
& $(0.014)$ \\
Industry: Dairy & $0.776^{* * *}$ \\
& $(0.193)$ \\
Industry: Felt & $0.108^{* * *}$ \\
& $(0.020)$ \\
Buddhist \% & $0.266^{* * *}$ \\
& $(0.026)$ \\
Distance to province centre & $-0.283^{* * *}$ \\
Constant & $(0.033)$ \\
& $0.001 * * *$ \\
Observations & $(0.000)$ \\
$R$-squared & $0.308^{* *}$ \\
\hline
\end{tabular}

Notes: Data source: Village and household survey. This table shows a regression to link village risk to various village-level characteristics. The first five variables are village averages of households reported to have experienced the mentioned shock within the last year (crop disaster, job loss, robbery, death, illness). The variable "Money transfers \%" is the average of households that reported to have received or given a monetary transfer from friends or family within the last year. "Under 16" and "Over 60" are village level averages of households that include at least one member below the age of 16 or above the age of 60 . Variables "Industry: Dairy" and "Industry: Felt" indicate whether one of the top three industries in the village is dairy or felt, respectively. "Buddhist \%" is the percentage of buddhists in the village. "Distance to province centre" is a continuous variable, indicating the number of kilometres between the village and the province centre. Robust standard errors in parentheses. ***, $* *$ * denote significance at the $1 \%, 5 \%$ and $10 \%$ level.

\section{Appendix D: Who Takes up Loans?}

One might expect that the joint-liability contract perhaps attracted a group of people that was different from the group that took up individual-liability loans. Table D.1 presents a statistical comparison between the women that took up a loan in the jointliability and those in the individual-liability villages. For each variable we present the baseline mean for the individual-lending treatment group (in the post-attrition sample) as well as the difference in means between the individual and the joint-liability borrowers (with a p-value for a t-test of equality of these means). 
TABLE D.1. Comparison of borrowers in individual versus joint-liability villages.

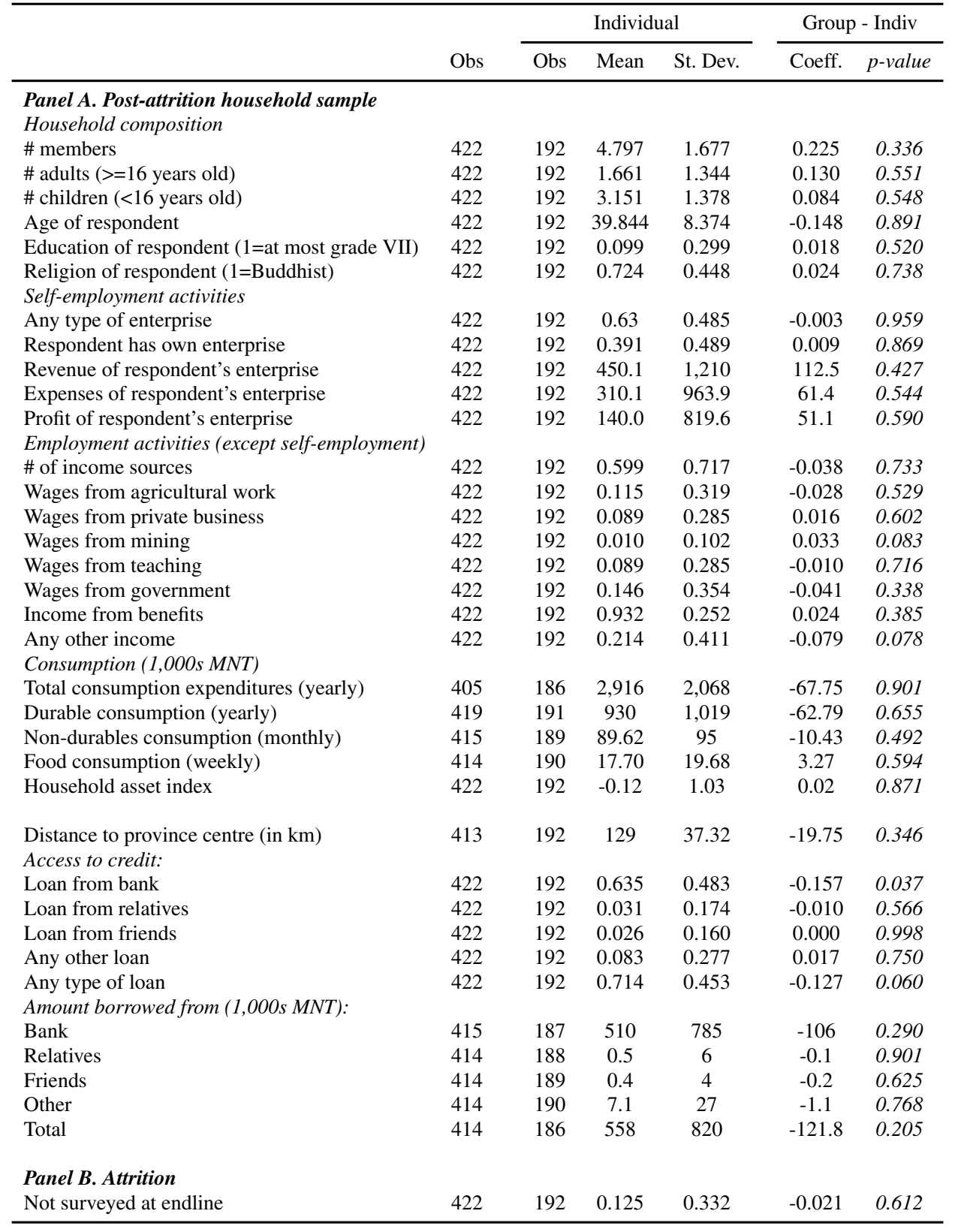

Notes: Data source: baseline household survey. Unit of observation: household. Panel A: sample includes only households of respondents who took up a loan and who were surveyed at endline. Panel B: sample includes all households surveyed at baseline. In case of household characteristics, the standard errors are clustered at the village level. Wages from private business includes wages from working in a shop, market, bank, finance company, or other private business. 1,000s MNT: Thousands of Mongolian tögrög. The exchange rate at baseline was USD 1 to MNT 1,150 . 
The table shows very few significant differences between individual-liability and joint-liability borrowers along a large number of observable characteristics. For instance, we find no significant differences in terms of household composition; borrower characteristics such as age, education, and religion); the types of selfemployment activities; consumption expenditures; and location (distance to province centre). The only difference we observe is one in terms of initial credit access. Women taking loans in joint-liability villages are slightly less likely to have a loan with a bank at baseline (significant at 5\% level). However, this does not translate into a statistically significant difference in terms of the amount of total outstanding debt at baseline. When we control for initial debt (Table E.1 in Appendix E) all our results continue to go through.

\section{Appendix E: Additional tables}

TABLE E.1. Robustness - Additional interaction terms.

\begin{tabular}{|c|c|c|c|c|c|}
\hline & $\begin{array}{c}\text { Baseline } \\
\text { (1) }\end{array}$ & $\begin{array}{l}\text { Highly } \\
\text { educated } \\
\text { (2) }\end{array}$ & $\begin{array}{l}\text { Loans at } \\
\text { baseline } \\
\text { (3) }\end{array}$ & $\begin{array}{c}\text { Enterprise } \\
\text { baseline } \\
\text { (4) }\end{array}$ & $\begin{array}{c}\text { Risk } \\
\text { aversion } \\
(5)\end{array}$ \\
\hline Joint Liability (JL) & $\begin{array}{c}-0.606^{* * *} \\
(-2.92)\end{array}$ & $\begin{array}{c}-0.493^{* *} \\
(-2.06)\end{array}$ & $\begin{array}{c}-0.594^{* * *} \\
(-2.63)\end{array}$ & $\begin{array}{l}-0.289 \\
(-0.62)\end{array}$ & $\begin{array}{c}-0.486^{* *} \\
(-2.52)\end{array}$ \\
\hline Investment risk, $\mathrm{CV}$ & $\begin{array}{c}-3.711^{* * *} \\
(-2.62)\end{array}$ & $\begin{array}{c}-3.671^{* * *} \\
(-2.62)\end{array}$ & $\begin{array}{c}-3.688^{* * * *} \\
(-2.59)\end{array}$ & $\begin{array}{c}-3.694^{* * *} * \\
(-2.79)\end{array}$ & $\begin{array}{c}-3.427^{* * *} \\
(-2.58)\end{array}$ \\
\hline $\mathrm{JL} *$ Investment Risk & $\begin{array}{l}4.852^{* * * *} \\
\quad(2.70)\end{array}$ & $\begin{array}{c}4.689^{* * *} \\
(2.65)\end{array}$ & $\begin{array}{c}4.806^{* * *} \\
\quad(2.61)\end{array}$ & $\begin{array}{c}4.140^{* *} \\
(2.12)\end{array}$ & $\begin{array}{c}3.435^{* *} \\
(2.16)\end{array}$ \\
\hline Average expected return (ER) & $\begin{array}{c}0.0969 \\
(0.73)\end{array}$ & $\begin{array}{l}0.0804 \\
(0.62)\end{array}$ & $\begin{array}{l}0.0976 \\
(0.74)\end{array}$ & $\begin{array}{c}0.0185 \\
(0.16)\end{array}$ & $\begin{array}{l}0.134 \\
(0.93)\end{array}$ \\
\hline $\mathrm{JL} * \mathrm{ER}$ & $\begin{array}{c}-0.0473 \\
(-0.33)\end{array}$ & $\begin{array}{c}-0.0296 \\
(-0.21)\end{array}$ & $\begin{array}{c}-0.0468 \\
(-0.33)\end{array}$ & $\begin{array}{c}0.0356 \\
(0.23)\end{array}$ & $\begin{array}{l}-0.128 \\
(-0.84)\end{array}$ \\
\hline Covariate $(\mathrm{X})$ & & $\begin{array}{c}0.0375 \\
(0.52)\end{array}$ & $\begin{array}{c}0.0556^{*} \\
(1.96)\end{array}$ & $\begin{array}{l}0.452 \\
(1.45)\end{array}$ & $\begin{array}{c}-0.0126 \\
(-0.82)\end{array}$ \\
\hline Interaction $X^{*} \mathrm{JL}$ & & $\begin{array}{l}-0.136 \\
(-1.29)\end{array}$ & $\begin{array}{c}-0.0117 \\
(-0.27)\end{array}$ & $\begin{array}{l}-0.425 \\
(-1.00)\end{array}$ & $\begin{array}{c}0.00977 \\
(0.35)\end{array}$ \\
\hline Household covariates & Yes & Yes & Yes & Yes & Yes \\
\hline Province FE & Yes & Yes & Yes & Yes & Yes \\
\hline$P$-value $(1+\mathrm{JL}) *$ Risk $=0$ & 0.497 & 0.542 & 0.507 & 0.797 & 0.996 \\
\hline $\mathrm{N}$ & 829 & 829 & 829 & 829 & 686 \\
\hline
\end{tabular}

Notes: This table replicates column 2 from Table 5 in the first column after which the subsequent columns include additional interaction terms between baseline covariates and the joint liability dummy. Column 2 interact JL with an indicator for whether the household head is highly educated or not; column 3 with an indicator whether the household had loans outstanding at baseline or not; column 4 with an indicator of whether the household owned an enterprise at baseline or not; and column 5 with a measure of risk aversion. Robust standard errors clustered at the village level are shown in parentheses. *,**, *** indicates significance at the 10,5 and 1 percent level. 
TABLE E.2. Robustness - Imposing restrictions on expectations data.

\begin{tabular}{|c|c|c|c|c|}
\hline & \multicolumn{2}{|c|}{ Without restrictions } & \multicolumn{2}{|c|}{ With restrictions } \\
\hline & $\begin{array}{l}\text { Village-level } \\
\text { risk } \\
(1)\end{array}$ & $\begin{array}{l}\text { Individual- } \\
\text { level risk } \\
\text { (2) }\end{array}$ & $\begin{array}{l}\text { Village-level } \\
\text { risk } \\
\text { (3) }\end{array}$ & $\begin{array}{l}\text { Individual- } \\
\text { level risk } \\
\text { (4) }\end{array}$ \\
\hline Joint Liability (JL) & $\begin{array}{c}-0.606^{* * *} \\
(-2.92)\end{array}$ & $\begin{array}{l}0.0700 \\
(1.48)\end{array}$ & $\begin{array}{c}-0.655^{* * *} \\
(-3.46)\end{array}$ & $\begin{array}{c}0.0803^{*} \\
(1.66)\end{array}$ \\
\hline Investment risk, $\mathrm{CV}$ & $\begin{array}{c}-3.711^{* * *} \\
(-2.62)\end{array}$ & $\begin{array}{c}-4.578^{* * *} \\
(-3.21)\end{array}$ & $\begin{array}{c}-3.777^{* * *} \\
(-3.08)\end{array}$ & $\begin{array}{c}-1.833^{* * *} \\
(-2.87)\end{array}$ \\
\hline JL * Investment Risk & $\begin{array}{c}4.852^{* * *} \\
(2.70)\end{array}$ & $\begin{array}{c}5.820^{* * *} \\
(4.77)\end{array}$ & $\begin{array}{c}4.867^{* * *} \\
(3.26)\end{array}$ & $\begin{array}{c}2.154^{* * *} \\
(2.84)\end{array}$ \\
\hline Average expected return (ER) & $\begin{array}{c}0.0969 \\
(0.73)\end{array}$ & $\begin{array}{l}0.140 \\
(1.42)\end{array}$ & $\begin{array}{c}-0.00566 \\
(-0.05)\end{array}$ & $\begin{array}{c}0.0381 \\
(0.42)\end{array}$ \\
\hline $\mathrm{JL} * \mathrm{ER}$ & $\begin{array}{c}-0.0473 \\
(-0.33)\end{array}$ & $\begin{array}{c}-0.111^{*} \\
(-1.74)\end{array}$ & $\begin{array}{c}0.0540 \\
(0.45)\end{array}$ & $\begin{array}{c}0.0008 \\
(0.01)\end{array}$ \\
\hline Household covariates & Yes & Yes & Yes & Yes \\
\hline Province FE & Yes & Yes & Yes & Yes \\
\hline$P$-value $(1+\mathrm{JL}) *$ Risk $=0$ & 0.497 & 0.345 & 0.199 & 0.580 \\
\hline Observations & 829 & 829 & 829 & 829 \\
\hline
\end{tabular}

Notes: This table provides robustness tests on restrictions on reported expectation data to estimate the relationship between microcredit liability structure, investment risk and loan demand (applications). Columns 1-2 replicate our results of columns 2 and 4 in Table 5 for ease of comparison. These are calculated without imposing any restricions. Columns 3-4 report similar regressins with two restrictions imposed: respondents who reported probabilities of zero or one as well as those whose reported probabilities that added up to more than 1.2 or less than 0.8 were excluded and imputations were used instead. In columns 1 and 3 investment risk is measured at the village level, in columns 2 and 4 at the individual level. Robust standard errors clustered at the village level are shown in parentheses. Covariates are the same as in Table 4. *,**,*** indicates significance at the 10, 5 and 1 percent level. 


\section{Appendix F: Subjective Expectation Data}

\section{Response Rates and Reporting of Probabilities}

Table F.1 provides information on response rates and the extent of inconsistencies in reporting probabilities, as discussed in Section 4.1 of the main text. The total number of observations (as shown in the first row of the table) in the matched household and loan data set used in this analysis is 836 . Of these respondents, $81 \%$ reported at the time of the baseline survey that they intend to use a loan from XacBank for productive purposes, that is, to invest into at least one enterprise. The remaining respondents reported to intend to use the loan to fund consumption (10\%), education expenses (3\%), general household expenses $(3 \%)$, health expenses $(1 \%)$, or "other" $(2 \%)$. The 679 respondents that intended to use a loan for a productive investment were further asked about their expectations about the returns to this investment. They were also asked the probability questions. Overall, $92 \%$ of respondents answered all four of these questions.

The remaining rows of the table provide details on the responses given to the probability questions. We see that - similar to the sample analysed by Attanasio et al. (2005) - 10\% (26\%) of households report a probability of 0 or 1 to the question of likelihood that the business revenue will be above (below) the midpoint between the minimum and maximum reported expected returns. We also report how many households report a probability of 0.5 and find this to be $12 \%$ on average. This again is similar to the $15 \%$ found by Attanasio et al. (2005). We do not exclude respondents that reported probabilities of zero or one but show in robustness tests in Table E.2 in Appendix $\mathrm{E}$ that our findings are very similar when imposing this assumption on the data.

The last two rows of Table F.1 provide descriptive statistics of the sum of the two reported probabilities. These should in theory add up to 1 but we refrained from imposing this restriction during the interviews. We find that the average sum of the reported probabilities is 1.26 . When excluding probabilities of zero and one, it decreases to 1.15. In our analysis, we do not exclude respondents whose reported probabilities do not add up to 100. Table E. 2 shows, however, that our results are robust to excluding respondents whose summed probabilities are above 120 or below 80 .

To gain a deeper understanding of the response rates, we check how the following three dependent variables covary with a large set of observable characteristics of the respondent and her household 25 , (i) an indicator for whether the household intends to invest the loan into an enterprise or not, (ii) an indicator for whether the respondent

25. We consider the following covariates: dummy for highly-educated household head (HH); dummy for married $\mathrm{HH}$; age (squared) of $\mathrm{HH}$; dummy for household with at least one member $>60$ years; dummy for household with at least one member $<16$ years; dummy for Buddhist or Hahl households. Additional covariates indicate economic status (ownership of dwelling, fence, well, vehicle, tools, animals); shocks experienced in the past year (crop disaster, illness, job loss, death in household); a dummy for outstanding debt; and the number of loans. 
TABLE F.1. Response rates and reporting probability.

\begin{tabular}{lc}
\hline Total number of observations & 836 \\
Number of respondents intending to use loan for enterprise & 679 \\
Percentage of respondents intending to use loan for enterprise & $81.2 \%$ \\
Expected minimum and maximum revenues provided & 633 \\
Both probabilities provided & 627 \\
& $92.3 \%$ \\
\hline & \\
Percentage of respondents with complete information & $63(10 \%)$ \\
& $76(12 \%)$ \\
No. (\%) of respondents reporting 0 or 1 to Prob(above) & $166(26 \%)$ \\
No. (\%) of respondents reporting 0.5 to Prob(above) & $73(12 \%)$ \\
No. (\%) of respondents reporting 0 or 1 to Prob(below) & \\
No. (\%) of respondents reporting 0.5 to Prob(below) & 1.26 \\
& 1.15 \\
\hline Mean of sum Prob(above)+Prob(below) & \\
Mean of sum Prob(above)+Prob(below), excluding Prob 0 and 1 & \\
\hline
\end{tabular}

This table provides summary statistics on the responses to questions on investment return expectations and probabilities.

gave answers to the expectation and probability questions, and (iii) an indicator for whether she gave a theoretically "incorrect" answer to any of the expectations questions.

This exercise shows that only very few covariates correlate significantly with any of these indicator variables. In particular, we find that the education level of the respondent is not predictive of non-reporting or mis-reporting. Furthermore, we find that respondents that owned an enterprise at baseline were both more likely to report to plan to use the loan for entrepreneurial activities and were also more likely to provide full answers to the set of expectations questions. The latter result likely reflects that existing entrepreneurs find it easier to provide return estimates as they already had prior business experience. The full results for these regressions are available from the authors upon request.

Lastly, we plot the average expected return against our risk measure (both at the individual level), as shown in the figure below. The solid line shows fitted values. As expected, the data show that with an increase in expected risk, also the expected return increases. 


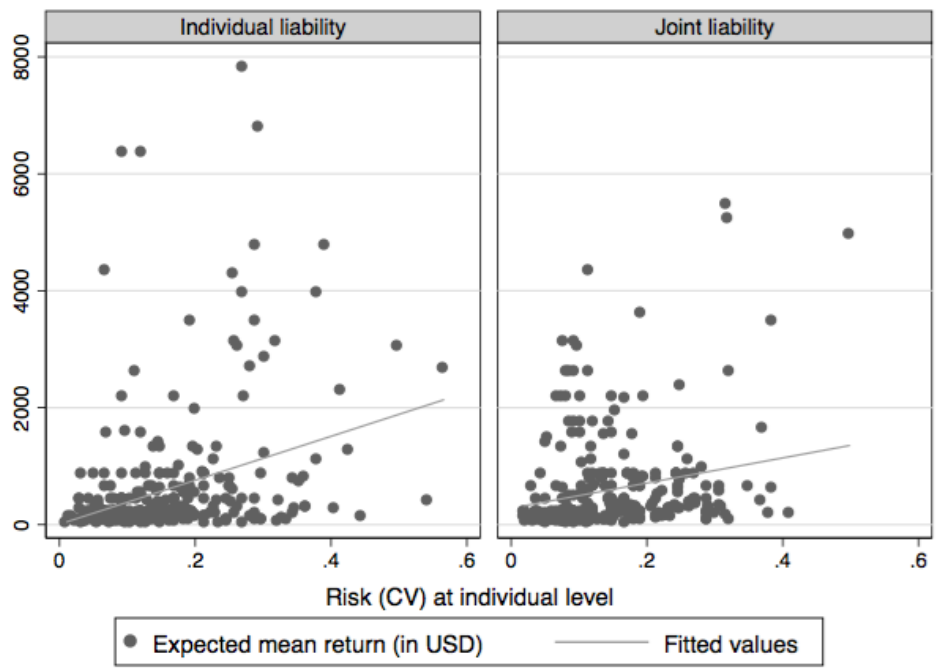

FIGURE F.1. Risk and expected return.

\section{References}

Ahlin, Christian (2009). "Matching for Credit: Risk and Diversification in Thai Microcredit Groups." BREAD Working Paper No. 251, Bureau for Research and Economic Analysis of Development.

Ahlin, Christian and Robert M. Townsend (2007). "Using Repayment Data to Test Across Models of Joint Liability Lending.” Economic Journal, 117(517), F11-F51.

Allen, Treb (2016). "Optimal (Partial) Group Liability in Microfinance Lending." Journal of Development Economics, 121, 201-216.

Angelucci, Manuela, Dean Karlan, and Jonathan Zinman (2015). "Microcredit Impacts: Evidence from a Randomized Microcredit Program Placement Experiment by Compartamos Banco." American Economic Journal: Applied Economics, 7(1), 151-182.

Attanasio, Orazio and Britta Augsburg (2016). "Subjective Expectations and Income Processes in Rural India." Economica, 83, 416-442.

Attanasio, Orazio, Britta Augsburg, Ralph De Haas, Emla Fitzsimons, and Heike Harmgart (2015). "The Impacts of Microfinance. Evidence from Joint-Liability Lending in Mongolia." American Economic Journal: Applied Economics, 7(1), 90-122.

Attanasio, Orazio and Vincenzo di Mario (2008). "Income Expectations in Rural Mexico. Measurement and Models." Mimeo.

Attanasio, Orazio, Costas Meghir, and Marcos Vera Hernandez (2005). "Elicitation, Validation and Use of Probability Distributions of Future Income in Developing Countries." Unpublished working paper presented at the 2005 Econometric Society Meeting.

Banerjee, Abhijit, Timothy Besley, and Timothy W. Guinnea (1994). "Thy Neighbour's Keeper: The Design of a Credit Cooperative with Theory and a Test." Quarterly Journal of Economics, 109, 491-515.

Banerjee, Abhijit, Emily Breza, Esther Duflo, and Cynthia Kinnan (2017). "Do Credit Constraints Limit Entrepreneurship? Heterogeneity in the Returns to Microfinance." Working paper, Buffett Institute Global Poverty Research Lab, No. 17-104.

Banerjee, Abhijit, Dean Karlan, and Jonathan Zinman (2015). "Six Randomized Evaluations of Microcredit. Introduction and Further Steps." American Economic Journal: Applied Economics, 
$7(1), 1-21$.

Beaman, Lori, Dean Karlan, Bram Thuysbaert, and Christopher Udry (2015). "Self-Selection into Credit Markets: Evidence from Agriculture in Mali.” Tech. rep., NBER Working Paper No. 20387.

Besley, Timothy and Stephen Coate (1995). "Group Lending, Repayment Incentives and Social Collateral." Journal of Development Economics, 46, 1-18.

Bohle, Bharat and Sean Ogden (2010). "Group Lending and Individual Lending with Strategic Default." Journal of Development Economics, 91, 348-363.

Cameron, A. Colin, Jonah B. Gelbach, and Douglas L. Miller (2008). "Bootstrap-Based Improvements for Inference with Clustered Errors." Review of Economics and Statistics, 90, 414427.

Carpena, Fenella, Shawn Cole, Jeremy Shapiro, and Bilal Zia (2013). "Liability Structure in SmallScale Finance: Evidence from a Natural Experiment." World Bank Economic Review, 27, 437469.

Coate, Stephen and Martin Ravallion (1993). "Reciprocity Without Commitment: Characterization and Performance of Informal Insurance Arrangements." Journal of Development Economics, 40, $1-24$.

De Quidt, Jonathan, Thiemo Fetzer, and Maitreesh Ghatak (2016). "Group Lending Without Joint Liability." Journal of Development Economics, 121, 217-236.

Delavande, Adeline, Xavier Giné, and David McKenzie (2011a). "Eliciting Probabilistic Expectations with Visual Aids in Developing Countries: How Sensitive Are Answers to Variations in Elicitation Design?" Journal of Applied Econometrics, 26, 479-497.

Delavande, Adeline, Xavier Giné, and David McKenzie (2011b). "Measuring Subjective Expectations in Developing Countries: A Critical Review and New Evidence." Journal of Development Economics, 94, 151-163.

Dominitz, Jeff and Charles F. Manski (1997). "Using Expectations Data to Study Subjective Income Expectations." Journal of the American Statistical Association, 92, 855-67.

Feigenberg, Benjamin, Erica Field, and Rohini Pande (2013). "The Economic Returns to Social Interaction: Experimental Evidence from Microfinance." Review of Economic Studies, 80, 145983.

Field, Erica and Rohini Pande (2008). "Repayment Frequency and Default in Micro-Finance: Evidence from India." Journal of the European Economic Association, 6, 501-9.

Field, Erica, Rohini Pande, John Papp, and Natalia Rigol (2013). "Does the Classic Microfinance Model Discourage Entrepreneurship among the Poor? Experimental Evidence from India." American Economic Review, 103, 2196-2226.

Fischer, Greg (2013). "Contract Structure, Risk Sharing, and Investment Choice.” Econometrica, 81, 883-939.

Fischer, Greg and Maitreesh Ghatak (2011). The Handbook of Microfinance, chap. Spanning the Chasm: Uniting Theory and Empirics in Microfinance Research, pp. 59-75. World Scientific Publishing.

Gangopadhyay, Shubhashis, Maitreesh Ghatak, and Robert Lensink (2005). "Joint Liability Lending and the Peer Selection Effect." Economic Journal, 115, 1005-15.

Ghatak, Maitreesh (1999). "Group Lending, Local Information and Peer Selection.” Journal of Development Economics, 60, 27-50.

Ghatak, Maitreesh (2000). "Screening by the Company You Keep: Joint Liability Lending and the Peer Selection Effect." Economic Journal, 110, 601-31.

Ghatak, Maitreesh and Timothy W. Guinnane (1999). "The Economics of Lending with Joint Liability: A Review of Theory and Practice." Journal of Development Economics, 60, 195-228.

Giné, Xavier, Pamela Jakiela, Dean Karlan, and Jonathan Morduch (2010). "Microfinance Games." American Economic Journal: Applied Economics, 2, 60-95.

Giné, Xavier and Dean Karlan (2014). "Group Versus Individual Liability: Long-Term Evidence from Philippine Microcredit Lending Groups.” Journal of Development Economics, 107, 65-83. 
Holt, Charles A. and Susan K. Laury (2002). "Risk Aversion and Incentive Effects." American Economic Review, 92, 1644-1655.

Johnston, Don and Jonathan Morduch (2008). "The Unbanked: Evidence from Indonesia." World Bank Economic Review, 22, 517-737.

Laffont, Jean-Jacques and Patrick Rey (2003). “Moral Hazard, Collusion, and Group Lending.” Tech. rep., Working Paper No. 122, Institut d'Economie Industrielle (IDEI), Toulouse.

Ligon, Ethan, Jonathan P. Thomas, and Tim Worrall (2002). "Informal Insurance Arrangements with Limited Commitment: Theory and Evidence from Village Economies." Review of Economic Studies, 69, 209-244.

Mahmud, Mahreen (2015). "Repaying Microcredit Loans: A Natural Experiment on Liability Structure.” Tech. rep., Working Paper KDPE No. 1509, University of Kent School of Economics.

McKenzie, David, John Gibson, and Steven Stillman (2013). "A Land of Milk and Honey with Streets Paved with Gold: Do Emigrants Have Over-Optimistic Expectations about Incomes Abroad?" Journal of Development Economics, 102, 116-127.

Meager, Rachael (2016a). "Aggregating Distributional Treatment Effects: A Bayesian Hierarchical Analysis of the Microcredit Literature." Tech. rep., Working Paper, MIT.

Meager, Rachael (2016b). "Understanding the Average Impact of Microcredit Expansions: A Bayesian Hierarchical Analysis of 7 Randomized Experiments." Tech. rep., Working Paper, MIT.

Mobarak, Ahmed Mushfiq and Mark R. Rosenzweig (2013). "Informal Risk Sharing, Index Insurance, and Risk Taking in Developing Countries." American Economic Review, 103, 375 80.

Sadoulet, Loïc (1999). "Equilibrium Risk-Matching in Group Lending." Tech. rep., ECARES/University Libre de Bruxelles.

Stiglitz, Joseph (1990). "Peer Monitoring and Credit Markets." World Bank Economic Review, 4, 351-366.

Wydick, Bruce (1999). "Can Social Cohesion be Harnessed to Repair Market Failures? Evidence from Group Lending in Guatemala." Economic Journal, 109, 436-475. 